\title{
The effects of seawater and nanosilica on the performance of blended cements and composites
}

\author{
Pawel Sikora $^{1,2}$ (D) $\cdot$ Didier Lootens $^{3} \cdot$ Maxime Liard $^{3} \cdot$ Dietmar Stephan $^{1}$ (i)
}

Received: 12 December 2019 / Accepted: 25 February 2020 / Published online: 9 March 2020

(c) The Author(s) 2020

\begin{abstract}
This study investigates the effects of seawater and nanosilica (3\% by weight of cement), on the fresh and hardened properties of cement pastes and mortars produced with two types of low heat cements: Portland pozzolana cement (CEM II) and blast furnace cement (CEM III). The heat of hydration, initial and final setting times, rheological properties, strength development, sorptivity and water accessible porosity of the cement pastes and mortars were determined. The data reveal that cement type has a significant effect on the reaction rate of cement with seawater and nanosilica (NS). Specimens produced with slag-blended cement exhibited a higher cement reaction rate and the composite produced exhibited better mechanical performance, as a result of the additional reaction of alumina rich phases in slag, with seawater. Replacement of freshwater with seawater contributes mostly to a significant improvement of early strength. However, in the case of slag-blended cement, 28 day strength also improved. The incorporation of NS results in additional acceleration of hydration processes, as well as to a decrease in cement setting time. In contrast, the addition of NS results in a noticeable increment in the yield-stress of pastes, with this effect being pronounced when NS is mixed along with seawater. Moreover, the use of seawater and NS has a beneficial effect on microstructure refinement, thus improving the transport properties of cement mortars. Overall, the study has showed that both seawater and NS can be successfully used to accelerate the hydration process of low heat blended cements and to improve the mechanical and transport properties of cement-based composites.
\end{abstract}

Keywords Nanosilica $\cdot$ Nanoparticles $\cdot$ Seawater $\cdot$ Blended-cement $\cdot$ Cement mortars $\cdot$ Slag $\cdot$ Pozzolan $\cdot$ Suevite $\cdot$ Hydration

\section{Introduction}

Concrete, a composite material composed of cement, water, aggregates and often admixtures, is the most produced man-made material in the world. Current, worldwide yearly production is at about 25 billion tones and its consumption

Submitted to the special issue of NANO-2019, within the 7th International Conference "Nanotechnologies and Nanomaterials" NANO-2019.

Pawel Sikora

pawel.sikora@zut.edu.pl

1 Building Materials and Construction Chemistry, Technische Universität Berlin, Gustav-Meyer-Allee 25, 13355 Berlin, Germany

2 Faculty of Civil Engineering and Architecture, West Pomeranian University of Technology Szczecin, Al. Piastow 50, Szczecin 70-311, Poland

3 Sika Technology AG-Central Research, Tueffenwies 16, Zürich CH-8048, Switzerland has been increasing gradually every year (Xiao et al. 2017; Wang et al. 2018). As a result, there has been a significantly increasing demand for its main components; that is, cement, water and aggregates. The production of Ordinary Portland Cement (OPC) is energy-intensive and contributes to about $5-7 \%$ of total anthropogenic $\mathrm{CO}_{2}$ emissions (Shaikh and Dobson 2019). Moreover, due to the over-exploitation of available deposits, sand and freshwater are now the two most valuable commodities of the twenty-first century (Etxeberria et al. 2016a; Dhondy et al. 2019). According to the United Nations (2019), over $40 \%$ of the world's population faces a scarcity of freshwater. This is particularly evident on isolated islands as well as in coastal and desert regions, where a shortage of freshwater has become a significant environmental threat. As a result of the high environmental impact of concrete production and the over-exploitation of natural resources, considerable pressure is continuously being exerted on the cement industry, to find alternative solutions aimed at decreasing resource use, saving energy as well as limiting greenhouse gas emissions (Bertola et al. 2019).

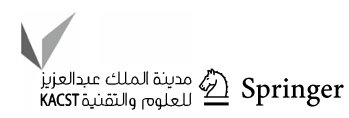


One of the most commonly used and widely accepted ways to improve the sustainability of cementitious composites is the production of so-called blended cements, obtained by partial replacement of OPC clinker with industrial by-products, such as ground-granulated blast furnace slag (GGBFS), fly ash (FA), silica fume (SF) or natural pozzolans and fillers like trass or limestone (Bentz et al. 2017; Shaikh and Dobson 2019). Although the use of various types of blended cements has been encouraged as a green solution, these composite cements suffer from lower hydration kinetics, which results in lower early strength development and is thus a drawback in many construction applications. To overcome this obstacle, various accelerating methods have been proposed, including the incorporation of nanomaterials such as nanosilica- $\mathrm{SiO}_{2}$ - which contributes to a significant acceleration of the cement hydration process. Various studies have confirmed the accelerating effects of nanosilica in OPC and blended cementitious systems (Singh et al. 2011; Abd El-Aleem and Ragab 2014, 2015; Heikal et al. 2016; Abdel Gawwad et al. 2017; Skoczylas and Rucińska 2018a, b; Yıldırım et al. 2018; Krivenko et al. 2019; Sikora et al. 2019a; Sanytsky et al. 2020).

Another direction being taken to improve the environmental friendliness of modern concretes, has been the recycling and reusing of mixing water. In recent decades, significant achievements have been made in reusing water from concrete production processes (Kucche et al. 2015), with the most recent substantial interest being placed on seawater as an alternative solution for impeding the exploitation of freshwater (Xiao et al. 2017; Li et al. 2018a; Dhondy et al. 2019; Jiangtao et al. 2019). Due to high desalination costs, as well as the high demand for concrete, there has been a keen interest in incorporating raw seawater in concrete (Wang et al. 2018; Younis et al. 2018). As water is an irreplaceable material, required to complete the hydration reaction with cement, its quality plays a crucial role in shaping the final mechanical and durability properties of cementitious composites. The chemicals in the water composition can interfere with cement and can thus have adverse effects on its setting and final properties. As a result, the composition of mixing water is regulated by certain standards (Basheer and Barbhuiya 2009; Kucche et al. 2015). According to standards such as ASTM C1602 or EN 1008, the use of seawater for the production of reinforced or prestressed concretes is prohibited, as seawater does not meet the limit of chloride content, thus resulting in high steel corrosion risk. However, recent technological improvements have, in some cases, made it possible to overcome this obstacle, by using corrosion-free reinforcements such as fiber-reinforced polymers (FRP) (Li et al. 2016, 2018b) or reinforcement-free ductile composites containing polypropylene (PP) fibers (Jiangtao et al. 2019). Moreover, the corrosion of reinforcing steel can be mitigated by creating a proper mixture design, which incorporates supplementary cementitious materials (SCMs) or corrosion inhibitors such as sodium nitrite (Otsuki et al. 2012; Lim et al. 2015; Tawfik et al. 2018).

Studies on the effects of seawater on the performance of cement-based composites have been widely conducted over the years. However, most of this work has been related solely to mechanical and durability evaluations of composites. Also, most of the available studies have focused on plain OPC systems. It is widely agreed that seawater has an accelerating effect of cement hydration processes (Govindarajan and Gopalakrishnan 2011; Li et al. 2018a; Younis et al. 2018; Montanari et al. 2019; Sikora et al. 2019b) and contributes to a decrease in the setting time and workability of concrete (Etxeberria et al. 2016b; Younis et al. 2018; Li et al. 2019; Teng et al. 2019). Early strength improvement, as an effect of accelerated cement hydration, has been widely reported (Demir et al. 2010; Wegian 2010; Otsuki et al. 2012; Abdel-Magid et al. 2016; Etxeberria et al. 2016a; Li et al. 2018a). After 28 days of curing, the effects of seawater in OPC-based concrete are considered to be minor and strength improvements (if at all observable) are generally limited to 5-10\%, with long-term mechanical performance being reported as slightly lower than that of OPC-based concrete produced with freshwater (Mbadike and Elinwa 2011; Etxeberria and Gonzalez-Corominas 2018; Guo et al. 2018; Bertola et al. 2019). Moreover, a refinement in pore structure and an improvement in the permeability of seawater-mixed composites has been reported (Ishikawa et al. 2014; Khatibmasjedi et al. 2019; Montanari et al. 2019; Sikora et al. 2019b).

The available literature studies suggest that the effect of seawater on the properties of cement-based composites is highly related to the type of cement used (Bautista et al. 2015; Bertola et al. 2019). Many authors have postulated that the use of FA, metakaolin (MK), or GGBFS, along with cement and seawater, increases the reaction ratio of cement, due to the additional interaction of SCMs with the components of the seawater (Bautista et al. 2015). It has also been widely reported that the incorporation of FA and seawater, besides improving early strength, results in improvement of the long term strength of concrete. Ishikawa et al. (2014) have reported that concretes containing a high volume of FA ( $>30 \mathrm{wt} \%$ by mass of cement) exhibit much higher compressive strength when using seawater for the mixing, as compared to corresponding concretes produced with freshwater. Similar conclusions have been reported elsewhere, when lower FA contents were incorporated into composites (Mohammed et al. 2004; Shaikh and Dobson 2019). Studies performed by Shi et al. (2015) and Cheng et al. (2018) have also confirmed the synergistic effects of MK and seawater, which lead to an improvement in the mechanical and microstructural properties of the concretes produced. However, very promising results have been reported when 
GGBFS, cement and seawater have been combined. Otsuki et al. (2012) have observed higher early age and long-term compressive strengths of seawater-mixed concretes, containing $70 \mathrm{wt} \%$ of cement replacement with GGBFS, as compared to the same concrete produced with freshwater. Studies undertaken by Etxeberria and Gonzalez-Corominas (2018) have shown that the combined effect of slag-blended cement (CEM III) and seawater, is more effective than OPC in decreasing permeability and improving the mechanical performance of concretes. The available studies suggest that the reaction rate of seawater with FA is lower than when GGBFS is used and that higher strength improvements and a lower concrete permeability a can be achieved when seawater is combined with GGBFS-blended cement (Otsuki et al. 2015). In addition, studies have shown that cementitious systems containing SCMs, especially GGBFS, exhibit high chloride binding ability; the concretes produced are thus less susceptible to corrosion of the reinforcing steel, when seawater is used as mixing water (Otsuki et al. 2015; Jun et al. 2017; Bertola et al. 2019). A recent comparative study by Li et al. (2018a) on the effects of GGBFS and SF on the early-age performance of cementitious composites mixed with seawater, showed that the presence of slag in the cement enhances the interaction with cement, due to the reactions triggered between the seawater components and hydration products rich in aluminum, with seawater decreasing the interaction of SF with cement. These observations are in line with the work of Demir et al. (2010), where only marginal effects of SF incorporation in concrete mixes with seawater were observed. In contrast, Sikora et al. (2019b) have recently reported the beneficial effect of combining nanosilica and seawater on the acceleration of hydration processes and the early strength development of OPC systems.

The effect of seawater on the hydration, microstructural and mechanical performance of cementitious composites, based on OPC, has recently been investigated by a number of researchers. However, there is still a lack of consensus as to the findings presented, with some conclusions being mutually exclusive. As a result, there is an urgent need for further research which will help in understanding the interactions and mechanisms underlying hydration and strength development of blended cementitious systems, mixed with seawater and modern admixtures, such as nanomaterials. As such, this study aims at evaluating the suitability of using the most popular nanosized admixture_-nanosilica (NS) — along with seawater, as a potential accelerating agent for pozzolan- and slag-blended cements. Accordingly, heat evolution, rheological measurements, setting times and compressive strength tests were performed, to characterize the synergistic effect of the presence of NS and seawater in blended cement systems. Accordingly, the cement pastes and cement mortars utilised were subsequently evaluated. Moreover, transport properties (open porosity and water sorptivity) of mortars were determined, to assess the role of seawater and NS in the interaction of blended cement systems.

\section{Materials}

\section{Cement and mortar paste components}

Two types of low hydration heat blended cements, conforming to EN 197-1, were used to produce the cement pastes and mortars used in this experiment: (1) Portland pozzolana cement CEM II/B-P $32.5 \mathrm{~N}$, containing suevite as a pozzolanic additive and produced by Märker Zement (Germany), as well as (2) blast furnace cement CEM III/A 32.5N-LH/ HSR/NA, produced by Cemex (Germany). To improve the readability, abbreviated names of cements: pozzolan- and slag-blended cement will be used, respectively. Chemical composition and physical properties of cements were summarized in Table 1. The particle size distributions (PSD) of the cements, measured using a laser diffraction analyzer (Malvern Mastersizer 2000, UK) are presented in Fig. 1. From the grading curve, it can be seen that the finesses of the pozzolan-cement was higher than that of the slag-containing cement, with d50 values of $14.1 \mu \mathrm{m}$ and $35.5 \mu \mathrm{m}$, respectively. Standardized quartz sand (0-2 $\mathrm{mm}$ ) conforming to EN 196-1, was used for the production of the cement mortars. Tap water meeting the requirements of EN 1008, was used as a source of freshwater. Artificial seawater with a salinity of $35.00 \%$ was prepared to confirm to the requirements of ASTM D1141-98, with its major components presented in Table 2.

\section{Nanosilica properties and characterization}

A commercially available suspension of colloidal silica (NS), with a density of $1.4 \mathrm{~g} / \mathrm{cm}^{3}$, was used in this study. The solid mass of the NS suspension was $50 \mathrm{wt} \%$ and as such, the
Table 1 Chemical composition and physical properties of cements

\begin{tabular}{lllllllllll}
\hline Type & $\mathrm{CaO}$ & $\mathrm{SiO}_{2}$ & $\mathrm{Al}_{2} \mathrm{O}_{3}$ & $\mathrm{Fe}_{2} \mathrm{O}_{3}$ & $\mathrm{MgO}$ & $\mathrm{Na}_{2} \mathrm{O}$ & $\mathrm{K}_{2} \mathrm{O}$ & $\mathrm{SO}_{3}$ & $\begin{array}{l}\text { Specific } \\
\text { density }(\mathrm{g} / \\
\left.\mathrm{cm}^{3}\right)\end{array}$ & $\begin{array}{l}\text { Surface area } \\
(\text { Blaine }) \\
\left(\mathrm{cm}^{2} / \mathrm{g}\right)\end{array}$ \\
\hline CEM II & 50.09 & 29.59 & 6.65 & 4.13 & 1.33 & 0.27 & 0.91 & 2.77 & 3.02 & 5560 \\
CEM III & 49.36 & 28.95 & 7.78 & 1.55 & 5.33 & 0.13 & 0.62 & 2.47 & 2.97 & 3900 \\
\hline
\end{tabular}




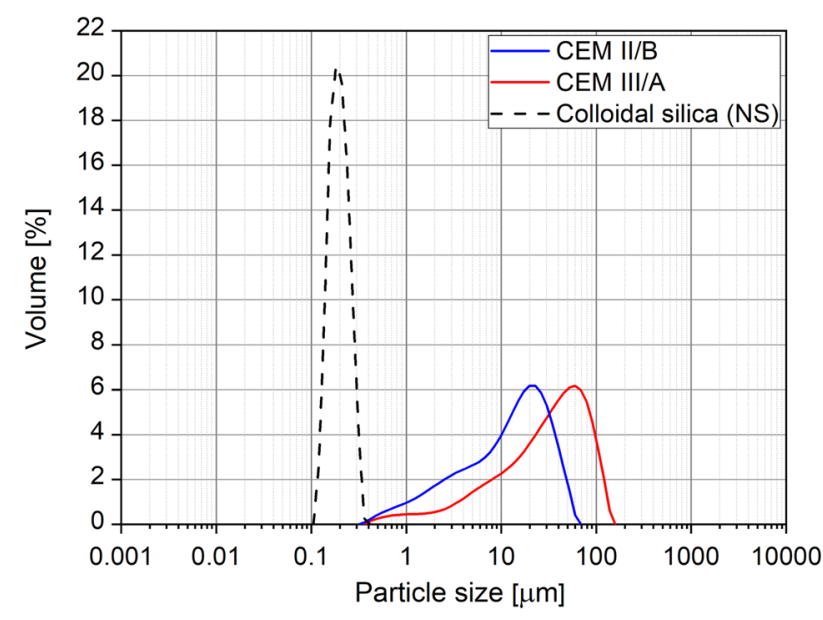

Fig. 1 Particle size distributions (PSD) of cements and colloidal silica (NS)

Table 2 Major components of seawater, as specified by ASTM D1141-98

\begin{tabular}{llllll}
\hline Type & $\mathrm{NaCl}$ & $\mathrm{MgCl}_{2}$ & $\mathrm{Na}_{2} \mathrm{SO}_{4}$ & $\mathrm{CaCl}_{2}$ & $\mathrm{KCl}$ \\
\hline Concentration $\left(\mathrm{g} / \mathrm{dm}^{3}\right)$ & 24.53 & 5.20 & 4.09 & 1.16 & 0.695 \\
\hline
\end{tabular}

liquid phase of the suspension was considered as a part the of mixing water in the production of the cement pastes and mortars. The same NS structures have been used in previous studies and have been comprehensively characterized in the work of Sikora et al. (2019b). High-resolution transmission electron microscope (TEM) micrographs (Fig. 2a-c) shows spherically shaped silica nanoparticles, with a energy dispersive X-ray (EDX) spectrum (Fig. 2e) and X-ray diffraction (XRD) patterns (Fig. 2f) confirming its high purity and amorphicity.

According to TEM analysis (Fig. 2d), NS sizes ranged from 10 to $140 \mathrm{~nm}$, while PSD obtained from laser diffraction (Fig. 1) showed NS distributions between 100 and $360 \mathrm{~nm}$, with a d50 of $181 \mathrm{~nm}$. Inconsistency in the results obtained from these two techniques have been commonly reported (Bretsnajdrova et al. 2010; Tuoriniemi et al. 2014; Babick 2016), with the higher values obtained from laser granulometry being associated mainly with the agglomeration of particles in aqueous media, during laser diffraction measurement (Quercia et al. 2013).
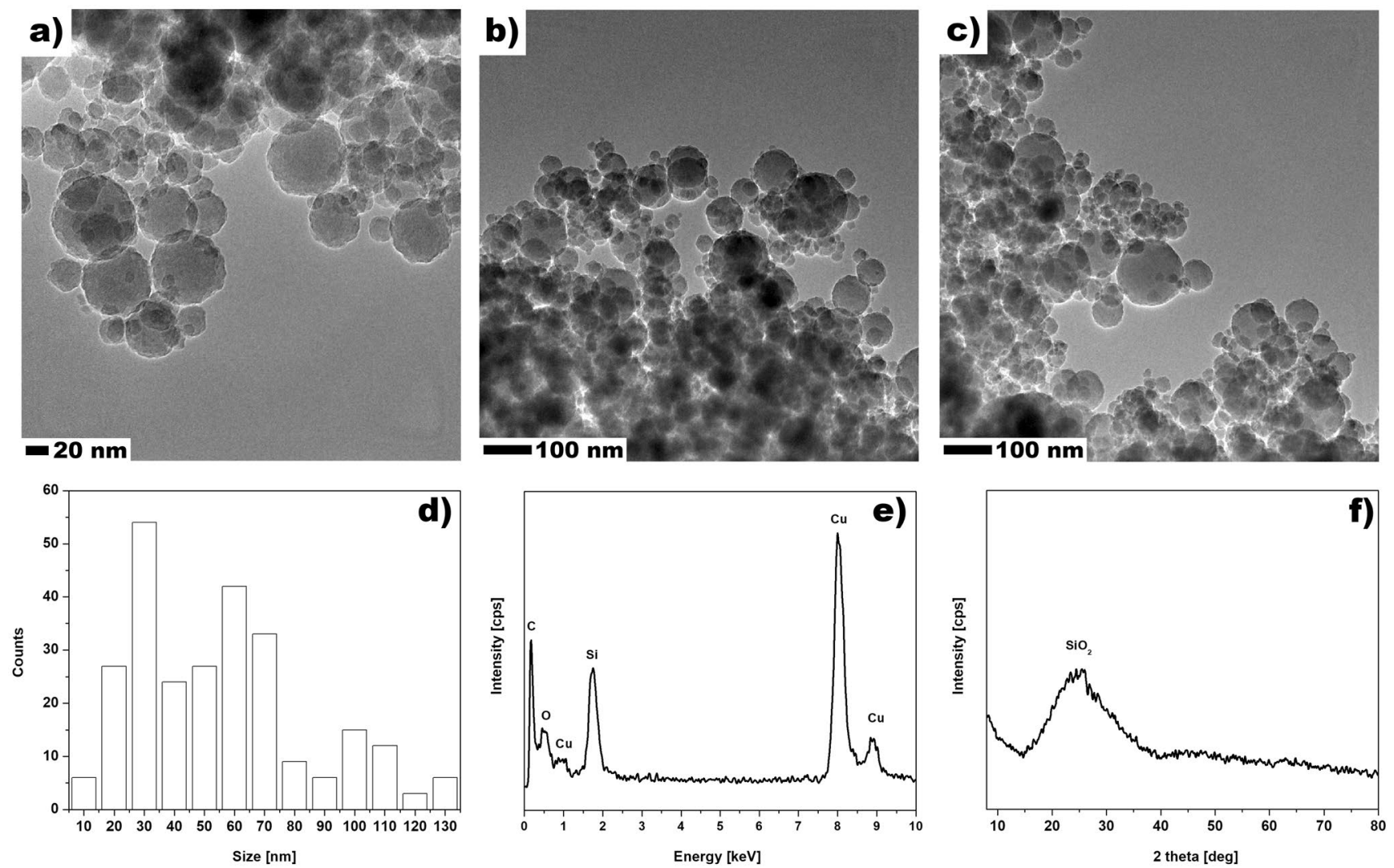

Fig. 2 TEM images (a-c), size distribution (d), EDX (e) and XRD (f) analysis of colloidal silica. The carbon and copper signals present in the spectrum come from the holey carbon TEM grid. Reproduced from Sikora et al. (2019b) 


\section{Cement paste mixture design}

In the first stage of this research, two sets of cement pastes containing pozzolan-blended cement (designated as $\mathrm{P}$ ) or slag-blended cement (designated as S), with either 0 or $3 \%$ (by weight of cement) nanosilica (NS), were produced. In addition, each type of paste was produced with either tap water (TW) or artificial seawater (SW). Specimens were designated in a way whereby the first two letters define the type of water used (TW or SW), the digit represents the NS dosage $(0,3)$, while the last letter refers to the type of cement used (P or S). For instance, SW3-S represents cement paste produced with slag-blended cement, seawater and $3 \mathrm{wt} \%$ of NS. The mixture compositions of the cement pastes is summarized in Table 3.

The water-to-cement (w/c) ratio of all the cement pastes was fixed at 0.5. As NS was used in suspension form, the mixing water was proportionally reduced to the amount of liquid content in the NS suspension. The NS in this study did not exceed $5 \mathrm{wt} \%$ and therefore the cement content remained fixed, in accordance with EN 943-2. The cement pastes were mixed using a standard laboratory mixer, conforming EN 196-1, according to the following procedure: (1) slow

Table 3 The composition of cement paste mixtures (g)

\begin{tabular}{llllll}
\hline & CEM II/B & CEM III/A & $\begin{array}{l}\text { NS } \\
\text { suspension }^{\text {a }}\end{array}$ & Water & Type of water \\
\hline TW0-P & 100 & - & - & 50 & Freshwater \\
TW3-P & 100 & - & 6 & 44 & Freshwater \\
SW0-P & 100 & - & - & 50 & Seawater \\
SW3-P & 100 & - & 6 & 44 & Seawater \\
TW0-S - & 100 & - & 50 & Freshwater \\
TW3-S - & 100 & 6 & 44 & Freshwater \\
SW0-S - & 100 & - & 50 & Seawater \\
SW3-S - & 100 & 6 & 44 & Seawater \\
\hline
\end{tabular}

a $50 \mathrm{wt} \%$ of solid mass mixing - $30 \mathrm{~s}$, (2) fast mixing - $1 \mathrm{~min}$, (3) break-1 min, (4) fast mixing - 1 min. Next, paste was poured into oiled molds to form $20 \times 20 \times 20 \mathrm{~mm}^{3}$ specimens. These specimens were then covered with foil and cured for $24 \mathrm{~h}$ in a climate chamber, with a relative humidity of $95 \%$ at room temperature $\left(20 \pm 1{ }^{\circ} \mathrm{C}\right)$. The specimens were cured in the same climate chamber for 28 days after demolding.

\section{Cement mortar mixture design}

In the second stage of research, cement mortars were produced based on cement pastes with added fine quartz aggregate. The ratio of cement to sand was set at $1: 3$, in accordance with EN 196-1. The mixture compositions of the cement mortars are summarized in Table 4.

Cement mortars were mixed using a standard laboratory mixer, according to EN 196-1. The consistency of the cement mortars was determined with the flow table method, conforming to EN 1015-3. The cement mortar was poured into $40 \times 40 \times 160 \mathrm{~mm}^{3}$ oiled molds, covered with foil and cured for $24 \mathrm{~h}$ in a climate chamber with a relative humidity of $95 \%$, at room temperature $\left(20 \pm 1{ }^{\circ} \mathrm{C}\right)$. After demolding, specimens were cured in water $\left(20 \pm 1^{\circ} \mathrm{C}\right)$ for 28 days.

\section{Methods}

\section{Isothermal calorimetry}

The hydration heat of the cement pastes was determined by an isothermal conduction calorimeter (TAM Air 3 calorimeter, TA Instruments). To track the hydration kinetics, $5 \mathrm{~g}$ of water was mixed with NS (if applicable) and $10 \mathrm{~g}$ of cement and then mixed for $1 \mathrm{~min}$. Immediately after mixing, the hydration heat of the samples was measured for 7 days. So as to better understand the test results, the acceleration rate of cement hydration was calculated, using the following equation (Eq. 1):
Table 4 The composition of cement mortar mixtures (g)

\begin{tabular}{llllllll}
\hline & CEM II/B & CEM III/A & Quartz sand & $\begin{array}{l}\text { NS } \\
\text { suspension }^{\text {a }}\end{array}$ & Water & Type of water & $\begin{array}{l}\text { Consist- } \\
\text { ency } \\
(\mathrm{mm})\end{array}$ \\
\hline TW0-P & 500 & - & 1500 & - & 250 & Freshwater & 160 \\
TW3-P & 500 & - & 1500 & 30 & 235 & Freshwater & 151 \\
SW0-P & 500 & - & 1500 & - & 250 & Seawater & 155 \\
SW3-P & 500 & - & 1500 & 30 & 235 & Seawater & 141 \\
TW0-S & - & 500 & 1500 & - & 250 & Freshwater & 170 \\
TW3-S & - & 500 & 1500 & 30 & 235 & Freshwater & 162 \\
SW0-S & - & 500 & 1500 & - & 250 & Seawater & 165 \\
SW3-S & - & 500 & 1500 & 30 & 235 & Seawater & 154 \\
\hline
\end{tabular}

${ }^{\mathrm{a}} 50 \mathrm{wt} \%$ of solid mass 
Acceleration rate $=\frac{H_{\mathrm{i}}-H_{\mathrm{c}}}{H_{\mathrm{c}}} \cdot 100 \%$,

where $H_{\mathrm{i}}$ corresponds to the cumulative heat (normalized by cement mass) of the selected sample and where $H_{\mathrm{c}}$ corresponds to the cumulative heat (normalized by cement mass) of the reference paste (either 0TW-P or 0TW-S).

\section{Setting time of cement pastes}

Initial and final setting time of the cement pastes was determined using an 8-cell compact, custom-built, non-commercial ultrasonic device containing three ultrasonic shear wave transducers bonded to a wave guide per cell. This device has been already successfully applied for in situ measurements of the setting time of cementitious composites, with full details of the device presented in Meacci et al. (2016). After mixing, the cement pastes were directly poured into the cells, aligned and covered with plastic foil to avoid water evaporation. Each measurement was performed with three repetitions, with the mean values taken as being representative.

\section{Rheological measurements}

To evaluate the rheological measurements of the cement pastes, a MCR 301 stress imposed rheometer equipped with a calibrated (Olivas et al. 2017) heliocoidal geometry (Liard et al. 2014), especially designed for cement paste, was used (Ojeda-Farías et al. 2019). The following measuring procedure was applied: (1) pre-shearing for $30 \mathrm{~s}$ at a constant shear-rate of $200 \mathrm{~s}^{-1}$, (2) determination of shear-stress as a function of the shear-rate, from 200 to $0.05 \mathrm{~s}^{-1}$, with 20 points evenly distributed in logarithmic scale, for a total of $300 \mathrm{~s}$. Significant efforts were made to ensure that no air was entrapped during rheological testing, as this is known to have a significant effect on the measurement results (Senff et al. 2009).

\section{Thermogravimetric analysis (TGA)}

Thermogravimetry (TG) was adopted in order to track changes in the calcium hydroxide $(\mathrm{CH})$ content of specimens after 7 and $28 \mathrm{~d}$ of curing. Measurement was performed with a TG 209 Tarsus F3 (Netzsch) instrument, under a nitrogen atmosphere and at a flow rate of $250 \mathrm{ml} / \mathrm{min}$. After 7 and 28 days of curing, the specimens were crushed and ground. Isopropanol was used to stop any hydration reactions in the powdered samples, after which the samples were well dried. In the TG procedure, the sample was first held at $25^{\circ} \mathrm{C}$ for $20 \mathrm{~min}$ and then heated from $25^{\circ} \mathrm{C}$ to $1000{ }^{\circ} \mathrm{C}$ at $10.00 \mathrm{~K} /$ $\min$.

To determine the $\mathrm{CH}$ content of the specimens, the mass drop in the thermogravimetric curve, at temperatures between 400 and $500{ }^{\circ} \mathrm{C}$, was calculated directly from the thermogravimetric curves using the following equation (Eq. 2):

$\mathrm{CH}(\%)=\mathrm{WL}_{\mathrm{CH}}(\%) \cdot \frac{\mathrm{MW}_{\mathrm{CH}}}{\mathrm{MW}_{\mathrm{H}}}$,

where $\mathrm{WL}_{\mathrm{CH}}$ corresponds to the percentage mass loss attributable to $\mathrm{CH}$ dehydration and where $\mathrm{MW}_{\mathrm{CH}}$ and $\mathrm{MW}_{\mathrm{H}}$ are the molecular weights of $\mathrm{CH}(74 \mathrm{~g} / \mathrm{mol})$ and water $(18 \mathrm{~g} /$ mol), respectively (Scrivener et al. 2016).

\section{Flexural and compressive strength evaluation}

Determination of the flexural and compressive strengths of the cement pastes and mortars produced was performed with the use of compression and flexural testing machines (Toni Technik, Berlin, Germany), conforming to EN 196-1 testing procedures. A compressive strength test of the cement pastes was carried out on $20 \times 20 \times 20 \mathrm{~mm}^{3}$ cubes after $1,2,3,7,14$ and 28 days of curing, using six samples for each mix. The flexural and compressive strength tests of the cement mortars were performed on $40 \times 40 \times 160 \mathrm{~mm}^{3}$ prismatic specimens after 2, 7 and 28 days of curing. The flexural strength of the cement mortars was determined first, after which, the compressive strength of the broken halves of specimens was tested. Three prisms were used for each test. In all experiments undertaken in this study, mean values and standard deviations were taken into consideration.

\section{Water accessible porosity and water sorptivity}

The transport properties of the mortars, including water accessible porosity and water sorptivity, were determined on $40 \times 40 \times 160 \mathrm{~mm}^{3}$ cement mortar prisms after 28 days of curing. The water accessible porosity $(P)$ of the mortars was determined using the water displacement method, with the saturated sample mass measured under water $\left(m_{\text {sub }}\right)$ after the curing period. The surfaces of the samples were subsequently dried followed by a determination of the mass of the saturated sample $\left(m_{\text {sat }}\right)$. The samples were then dried at $105{ }^{\circ} \mathrm{C}$ to a constant mass and weighed $\left(m_{\text {dry }}\right)$. Finally, the water accessible porosity was determined by applying Eq. (3).

$P(\%)=\cdot \frac{m_{\mathrm{sat}}-m_{\mathrm{dry}}}{m_{\mathrm{sat}}-m_{\mathrm{sub}}} \cdot 100 \%$.

The water sorptivity of the mortars was determined with the partial immersion method, following the guidelines of EN ISO 15148. Before the test, the sides of the specimens were coated with paraffin wax. During measurement, the water level was kept constant at about $5 \mathrm{~mm}$ above the highest point of the bottom side of the specimen, with changes in 
mass (water uptake) being determined at selected time intervals. Afterwards, based on the sorptivity curve, the water absorption coefficient was calculated as the ratio between the mass of water absorbed by the specimen, per area of suction and the square root of time.

\section{Results and discussion}

\section{Isothermal calorimetry}

Table 5 presents selected heat flow parameters (the time of the maximum exothermic peak and its maximum value) as well as the values of the cement acceleration rate calculated from Eq. (1). As illustrated in Fig. 3, in both types of cements, seawater clearly accelerated the kinetics of cement hydration. However, in the case of pozzolan-blended cement (Fig. 3a) one clear peak (silicate peak) can be observed in slag-blended cement (Fig. 3b), with the presence of an additional, second noticeable peak, related to the renewed formation of ettringite. The acceleration of cement hydration in the presence of seawater is represented in both an increment in the exothermic peak value, as well as in the decreased silicate peak occurrence time. The maximum heat flow of TW0-P and SW0-P was measured as $2.0 \mathrm{~mW} / \mathrm{g}$ and $3.0 \mathrm{~mW} / \mathrm{g}$, respectively, while the time required to reach the maximum value decreased from $10 \mathrm{~h} 12 \mathrm{~min}$ (TW0-P) to $8 \mathrm{~h}$ $54 \mathrm{~min}$ (SW0-P). In the case of slag-blended cement, seawater had a more pronounced effect on the hydration process, as compared to pozzolan-blended cement. The maximum heat flow of TWO-S and SWO-S were measured as $1.8 \mathrm{~mW} / \mathrm{g}$ and $2.3 \mathrm{~mW} / \mathrm{g}$ (respectively), while the time required to reach the peak decreased from $11 \mathrm{~h} 24 \mathrm{~min}$ (TW0-S) to $9 \mathrm{~h}$ 6 min (SW0-S). Similarly, a second peak, related mainly to the secondary hydration of $\mathrm{C}_{3} \mathrm{~A}$, clearly intensified in the seawater-mixed paste.

The addition of NS to the mixture clearly facilitated the hydration reaction from the very beginning of the hydration process. The maximum exothermic peak values increased in both types of cements. Furthermore, a decrement in the time
Table 5 Selected parameters of heat flow and the acceleration rate of cement hydration

\begin{tabular}{|c|c|c|c|c|c|c|c|}
\hline & \multicolumn{2}{|c|}{ Silicate peak } & \multicolumn{5}{|c|}{ Acceleration rate $(\%)$} \\
\hline & $\begin{array}{l}\text { Heat flow } \\
(\mathrm{mW} / \mathrm{g})\end{array}$ & Peak time (h) & $12 \mathrm{~h}$ & 1 day & 2 days & 3 days & 7 days \\
\hline TW0-P & 2.3 & 10.2 & 0.0 & 0.0 & 0.0 & 0.0 & 0.0 \\
\hline SW0-P & 3.0 & 8.9 & 21.1 & 13.8 & 6.1 & 5.7 & 2.5 \\
\hline TW3-P & 2.5 & 9.3 & 11.2 & 8.0 & 3.4 & 2.7 & 2.7 \\
\hline SW3-P & 3.1 & 8.5 & 28.7 & 18.6 & 8.4 & 7.4 & 4.3 \\
\hline TW0-S & 1.8 & 11.4 & 0.0 & 0.0 & 0.0 & 0.0 & 0.0 \\
\hline SW0-S & 2.3 & 9.1 & 24.6 & 17.5 & 12.7 & 14.2 & 10.2 \\
\hline TW3-S & 1.9 & 9.8 & 13.0 & 8.2 & 2.0 & 1.9 & 2.8 \\
\hline SW3-S & 2.5 & 8.0 & 41.7 & 31.3 & 18.7 & 19.1 & 13.2 \\
\hline
\end{tabular}
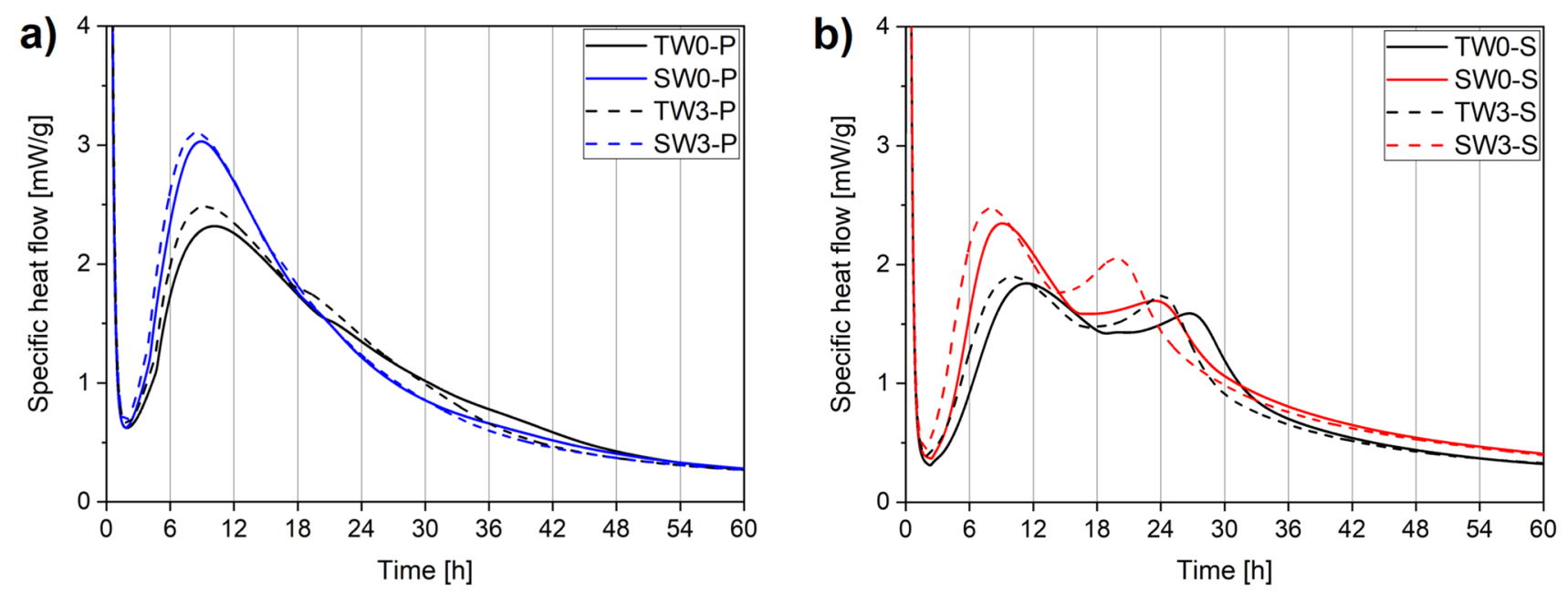

Fig. 3 Heat flow of pozzolan-blended cement (a) and slag-blended (b) cement 
required to reach the maximum rate was observed. It has been reported that silica nanoparticles, due to their ultrafine size, act as a nucleus for cement hydration, which results in faster formation of $\mathrm{CH}$ and more dynamic consumption of tricalcium silicate phase $\left(\mathrm{C}_{3} \mathrm{~S}\right)$ during the binding period; in turn, this results in an accelerated cement hydration process (Xu et al. 2016; Flores et al. 2017; Kotsay 2017; Potapov et al. 2019). As a result, the combination of seawater with NS resulted in a substantial acceleration of the hydration process. In the SW3-P and SW3-S specimens, the exothermic peak value increased by $35 \%$ and $39 \%$, with a simultaneous reduction in the time required to reach their peaks; by $1 \mathrm{~h} 42 \mathrm{~min}$ and $3 \mathrm{~h} 24 \mathrm{~min}$, respectively, as compared to the corresponding control specimens, TW0-P and TW0-S.

An analysis of cement hydration acceleration rate values (Table 5) shows different trends, depending on the cement type used. In both cases, a noticeable acceleration of the cement hydration process was observed in the first $24 \mathrm{~h}$ of hydration, but a much higher and extended intensity of the reaction was evident in the case of the slag-blended cement. The cumulative heat released by specimens SW0-P and SW0-S, after $12 \mathrm{~h}$ of hydration, was $21.1 \%$ and $24.6 \%$ (respectively) higher, as compared to their corresponding pastes made with freshwater. However, the ratio of accumulated heat between freshwater- and seawater-mixed specimens in pozzolan-blended cement, decreased gradually, while in slag-blended cement at up to 7 days of hydration, the seawater-mixed specimens exhibited substantially higher values of released heat. Furthermore, the addition of NS contributed significantly to an increase in released heat, especially in the case of slag-blended cement, with specimen SW3-S releasing, respectively, $41.4 \%, 31.3 \%$, and $18.7 \%$ more heat after $12 \mathrm{~h}, 1$ day and 2 days of hydration, as compared to TW0-S. These observations are in line with the available literature, confirming that seawater significantly affects the hydration process at an early age. However, the reaction rate is highly related to the type of cement used. In distinction to pozzolan-blended cement, when mixed with seawater slag-blended cements exhibited over a $10 \%$ higher heat release rate after 7 days of curing, with a combination of NS and seawater resulting in a $13.2 \%$ higher release rate. This confirms that a combination of seawater with slag-cement has a higher reaction rate than that of pozzolan-blended cement. The acceleration of cement hydration in the presence of seawater is enhanced due to the input of chlorides, which are known to be efficient accelerating agents in the cement hydration process, mainly the $\mathrm{C}_{3} \mathrm{~S}$ phase (Govindarajan and Gopalakrishnan 2011; Otsuki et al. 2015; Etxeberria et al. 2016b; Fernanda et al. 2017; Parthasarathy et al. 2017). As has been widely reported ( $\mathrm{Li}$ et al. 2018a; Wang et al. 2018; Younis et al. 2018; Shaikh and Dobson 2019), the negatively charged $\mathrm{Cl}^{-}$on the surface of the cement, together with the presence of SCM particles, promotes cement compounds' dispersion and results in an enhancement in hydration. Furthermore, a reaction between the $\mathrm{NaCl}$ present in seawater and the hydration product of cement, namely $\mathrm{CH}$, results in the formation of $\mathrm{CaCl}_{2}$, a very effective accelerator. Cement hydration can thus be further promoted. However, when slag-blended cement is used, chlorides in seawater provide an alkaline environment which activates the slag and results in an increase in the reaction rate between the interstitial phases of the slag, particularly $\mathrm{C}_{3} \mathrm{~A}$, resulting in faster setting of cementitious composites (Otsuki et al. 2012; Etxeberria et al. 2016b; Li et al. 2018a). Moreover, the rate of reaction increase in slag-blended cement is not only restricted to the early days, with a higher hydration rate also reported in the long term, as has been reported in the literature and found to be the case in the present work (Otsuki et al. 2012, 2015). A similar observation has been reported by Shi et al. (2015) and Li et al. (2015), where a combination of seawater and metakaolin-another alumina rich material — was found to lead to a significantly improved cement hydration rate.

\section{Initial and final setting time}

Figure 4 presents the results of the initial and final setting times of cement pastes obtained from the compact ultrasound device. It can be seen that the initial and setting times of the two types of cement (TW0-P and TW0-S) were comparable, with a reduction resulting from the presence of seawater or NS in the mixtures. The incorporation of seawater in cement pastes has a significant effect in reducing cement setting times and shortening the interval between initial and final setting. This latter effect was especially pronounced in the specimen produced with slag-blended cement (SW0-S), where the initial and final setting times were reduced by $1 \mathrm{~h} 15 \mathrm{~min}$ and $2 \mathrm{~h} 51 \mathrm{~min}$, respectively, as compared to the control specimen (TW0-S). This is attributable to the

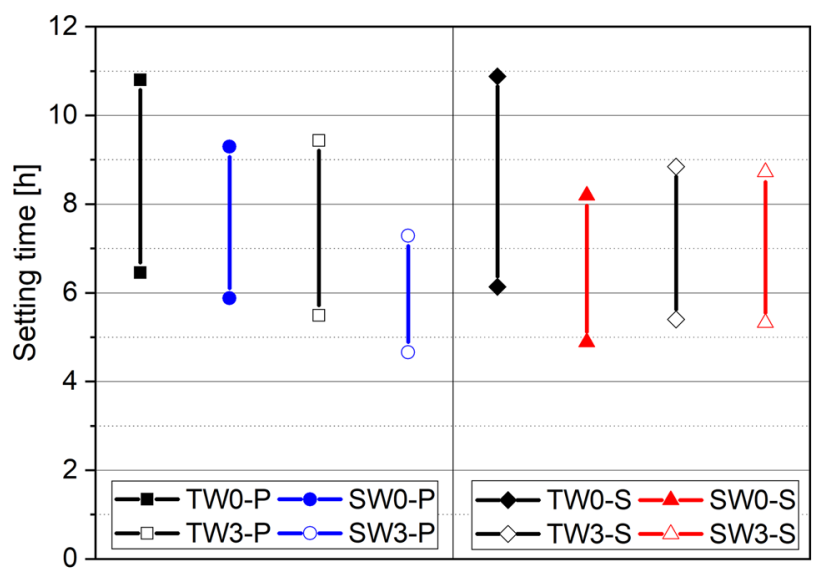

Fig. 4 Initial and final setting times of cement pastes 
reaction of seawater with $\mathrm{C}_{3} \mathrm{~A}$ (Etxeberria et al. 2016b), resulting in a faster setting of paste. A comparable reduction in setting times was observed with freshwater pastes, when NS was incorporated into the mixture (TW3-P and TW3-S). The most substantial reduction in setting time was reported in specimen SW3-P, where a combination of seawater and NS resulted in a decrement of the initial and final setting times by $1 \mathrm{~h} 48 \mathrm{~min}$ and $3 \mathrm{~h} 31 \mathrm{~min}$, respectively. In contrast, the addition of NS to slag-blended specimen with seawater (SW3-S), did not lead to a further reduction in setting time, with the values being comparable to that of the SW0-S specimen.

Similar observations regarding the reduction of setting times of cementitious composites mixed with seawater, have been reported elsewhere, with reductions in initial and final setting times usually ranging between 15 and 30\% (Kaushik and Islam 1995; Etxeberria et al. 2016a, b; Younis et al. 2018). Comparable values were reported in this study, with the initial and final cement paste setting times being reduced by $10 \%$ and $14 \%$ (respectively) for pozzolan-blended cement and by $20 \%$ and $25 \%$ for slag-blended cement. Similar behavior, regarding the stronger influence of seawater on decreases in slag-blended cement setting times, as compared with OPC, has been reported by Etxeberria et al. (2016b). The addition of NS has been shown to have a significant effect on decreasing the setting time of cement-based composites (Ye et al. 2007; Chen et al. 2016; Szymanowski and Sadowski 2019) and thus a combination of seawater and NS leads to further decreases in the setting time of pastes. In the case of pozzolan-blended cement, a combination of seawater and NS (SW3-P) leads to a reduction of initial and final setting times by $28 \%$ and $32 \%$. However, in the case of the slag-blended cement mixture with SW and NS (SW3-S), there was a reduction in setting time comparable to that of SW0-S, where only seawater was used.

\section{Rheological measurements}

Figure 5 presents the rheological behavior of fresh cement pastes as a function of shear rate. In comparing both figures, it can be seen that the pastes prepared with pozzolan-blended cement (Fig. 5a) always exhibited higher viscosities than corresponding mixes made with slagblended cement (Fig. 5b). This is a consequence of the difference in the particle size distribution of both cements (Fig. 1), with the pozzolan-blended cement displaying a narrower distribution with a higher proportion of small particles, thus leading to a higher cement surface area and a less optimal particle packing. In our experiments, the substitution of tap water by seawater induced a slight increase in the viscosity of pozzolan-blended cements paste, but did not significantly affect the slag-blended cement pastes. On the other hand, NS addition lead to important changes from a rheological point of view: the yield-stress increased by a factor of about 2.5 in the presence of tapwater and by a factor of about 4 with seawater. Similar changes have been observed experimentally and attributed to the extremely high surface area of NS, with the higher water demand of nanoparticles thus resulting in a reduction of the fluidity of specimens (Flores et al. 2017; Zhang et al. 2019). Furthermore, the higher the applied shear-rate, the lower the difference between curves with and without NS, with plastic viscosities then being expected to be in the same order of magnitude. The significant increase of the yield-stress in the presence of NS can therefore not be explained only by the
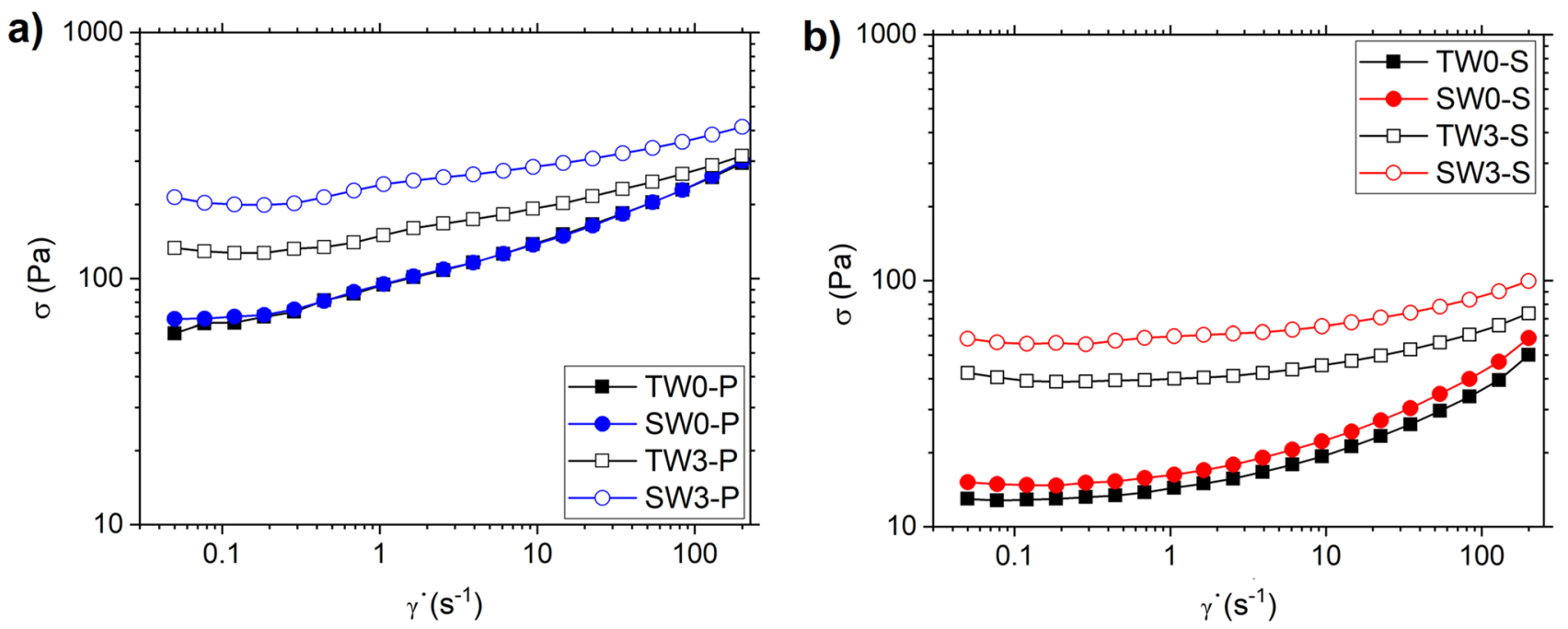

Fig. 5 Shear-stress as a function of the shear-rate of cement pastes produced with pozzolan-blended cement (a) and slag-blended cement (b) 
increase of the total solid content in the mix, but also by a drastic change in the microstructure of the paste at rest, with NS inducing a stronger flocculation of the particles in the system. Particles under shear start to deflocculate and thus the viscosity difference, with or without NS, decreases. This is also confirmed by the observation that yield-stress increase is even more significant in the presence of seawater, whose ions at high concentrations decrease the Debye-length of the NS, consequently leading to an even stronger flocculation of the system (Metin et al. 2011; Mijowska et al. 2015; Augustyniak et al. 2016; Daghlan Sofla et al. 2018; Wang et al. 2018).

\section{Consistency of cement mortars}

The results of consistency measurements of cement mortars, determined with a flow table, are summarized in Table 4. In general, the spread flow of pozzolan-based cement mortars was lower than that of slag-based cement mortars, due to a higher fineness of this type of cement (Fig. 1). Cement mortars mixed with seawater exhibited slightly decreased consistency, which is in line with observations made in the section above and in other studies (Etxeberria et al. 2016a; Younis et al. 2018; Li et al. 2019). The incorporation of NS leads to a more noticeable decrement in consistency, as a result of the high water absorption of NS particles (Liu et al. 2015; Ylldirim et al. 2018). A combination of seawater together with NS, resulted in the most significant reduction in the workability of mortars. Nevertheless, due to the relatively high initial w/c of the designed mortars, all mixtures were still workable and there was no need for the addition of superplasticizer.

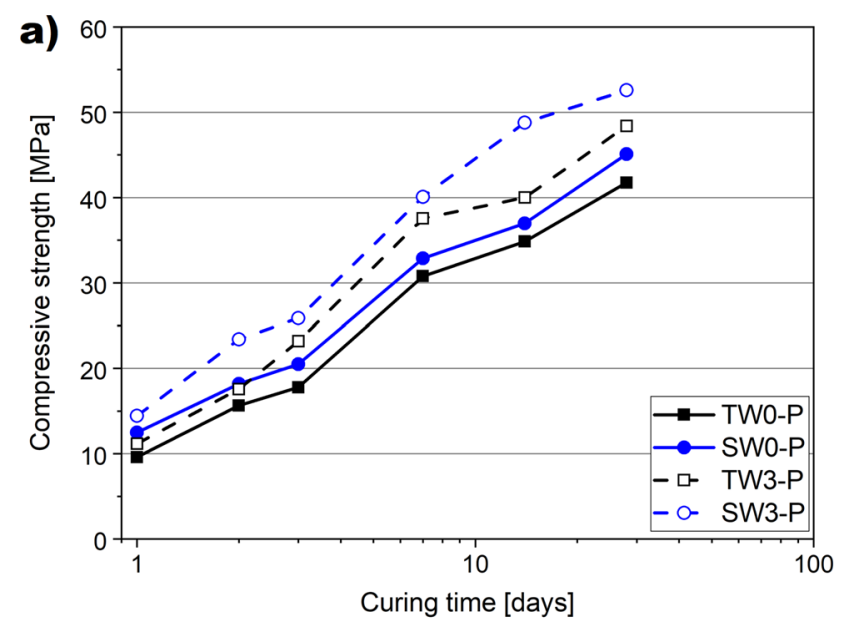

\section{Compressive strength of cement pastes}

The strength development of cement pastes produced with the two types of cement, is depicted in Fig. 6. It can be seen that from the first days of curing, both seawater and NS had a substantial accelerating effect on hydration, leading to a significantly higher compressive strength of specimens. However, depending on the type of cement used, the effects of the seawater and NS were varied. In the case of the pozzolan-blended cement (Fig. 6a), the most substantial effect of seawater was observed in the first 3 days of hydration, with the SW0-P specimen exhibiting between 15 and $30 \%$ higher compressive strength than TW0-P. From 7 to 28 days of curing, the ratio between the strength of freshwater- and seawater-mixed cement pastes was lower than $10 \%$. When NS was incorporated into freshwater cement paste, a significant acceleration of strength development was observed in the TW3-P specimen, for up to 7 days of hydration. This specimen exhibited $22 \%$ higher compressive strength than the TW0-P specimen, though after 28 days the improvement decreased slightly to $16 \%$. The beneficial effect of NS on early- and 28 day strength is attributable to three synergistic effects: first of all, ultrafine silica nanoparticles act as the nucleation sites (seeds) for the hydration reaction of the cement, thus accelerating cement hydration. In addition, nanosized NS particles fill the voids in cement paste, which facilitates the development of a compacted and refined cementitious composite microstructure. Moreover, NS particles exhibit intense pozzolanic activity and NS can react with free $\mathrm{CH}$, resulting in the production of additional amounts of C-S-H phase (Land and Stephan 2012; Skoczylas and Rucińska 2018b; Sikora et al. 2018; El-Feky et al. 2019). A combination of seawater and NS was the most beneficial for accelerating the strength development process

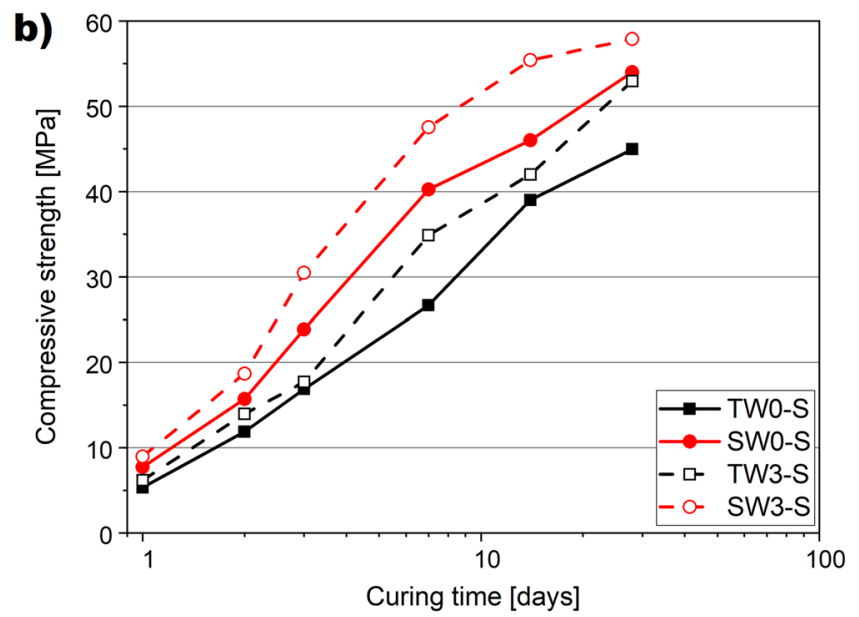

Fig. 6 Compressive strength development ( $x$-axis in logarithmic scale) of cement pastes containing pozzolan-blended cement (a) and slagblended cement (b) 
of cement pastes. In the first 3 days of hydration, SW3-P specimen exhibited over $45 \%$ higher compressive strength, as compared to TW0-P. It is worth noting that after 7 days of curing, SW3-P already exhibited higher compressive strength than TW0-P after 28 days of curing. A combination of NS and seawater resulted in further strength developments and at an age of 28 days, SW3-P exhibited 26\% higher compressive strength than the TW0-P specimen. In contrast, the strength development of cement pastes based on slag-blended cement exhibited different trends (Fig. 6b).

From the very beginning of the hydration process it can be seen that specimens containing seawater exhibited much higher strength development acceleration rates, even in comparison to the freshwater-mixed paste with NS (TW3$\mathrm{S})$. The results of the compressive strength test confirm the observation of the hydration study; that seawater is more efficient in accelerating slag-blended cement hydration, thus resulting in significant strength improvements. After 3 days of curing, specimens SW0-S and SW3-S exhibited over 40 and $80 \%$ higher compressive strengths than the TW0-S specimen and thus after 3 days of hydration, the cement pastes mixed with seawater already exhibited the 28 day strength value of the control (TW0-S) specimen. A combination of NS with seawater was highly beneficial for up to 28 days of hydration. After 28 days of curing, seawater-mixed cement paste exhibited $20 \%$ higher compressive strength. A combination of freshwater (TW3-S) with NS also had beneficial effects on the strength development of cement pastes, such that specimens TW3-S and SW3-S exhibited comparable strengths after 28 days of curing. The results obtained in this section were validated by the production of standardized cement mortars and an evaluation of their 2, 7 and 28 day compressive strengths.

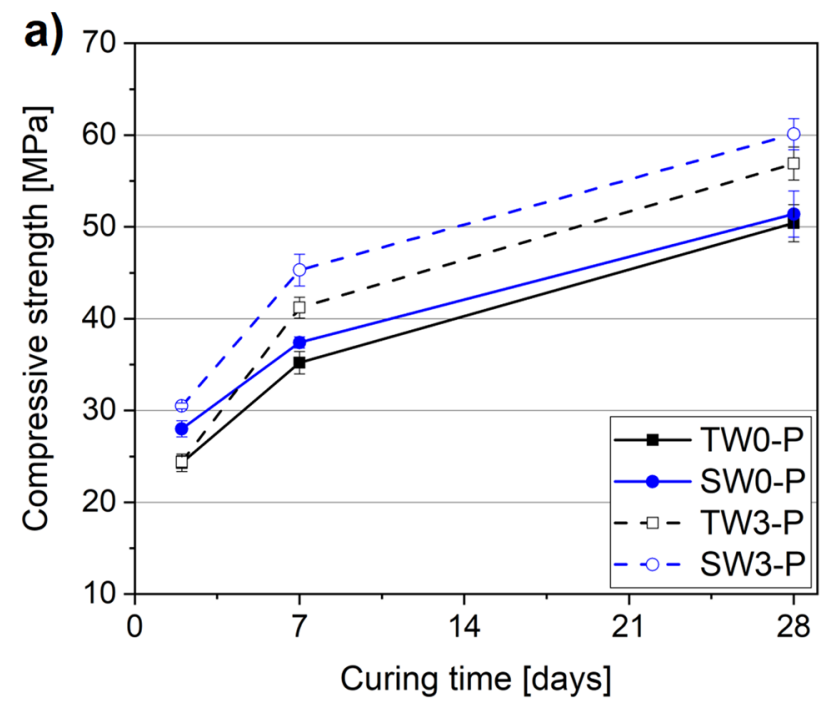

\section{Compressive strength of cement mortars}

In the second part of the research, cement mortars based on cement paste composition were produced to validate the findings of the previous section. It can be clearly seen in Fig. 7, that cement mortars follow the same strength development trends as were observed in the case of the cement pastes (Fig. 6). Again, no significance effects of seawater on 28 day compressive strength were reported in pozzolanblended cement mortars (Fig. 7a). However, mortar produced with slag-blended cement exhibited over $20 \%$ higher compressive strength value. Obviously, there are some small variations in results when the compressive strength development of cement paste and mortar are compared, but nevertheless the correlation coefficients between the cement pastes and mortars in all the mixes were over $98 \%$. To characterize the effects of the type of cement used and the presence of NS in the mixture, the relative compressive strength was calculated as a ratio between the selected specimen's strength at a certain day of hydration, divided by the strength of the corresponding control specimen (TW0-P or TW0-S) on the same day of testing (Fig. 8). These results confirm that the accelerating effect of seawater in pozzolan-blended cement (Fig. 8a), occurred mostly in the early days of hydration, while in case of mortars containing slag-blended cement, this effect was pronounced for up to 7 days with a gradual decrement at 28 days (Fig. 8b). In addition, the reaction rate was over two times higher when compared to the pozzolanblended cement mortar. The addition of NS to cement mortars in the first 2 days of hydration was not significant, with the effect being more pronounced after 7 days of curing; this is attributable to the additional pozzolanic activity of NS (Hou et al. 2015). The most beneficial compressive strength

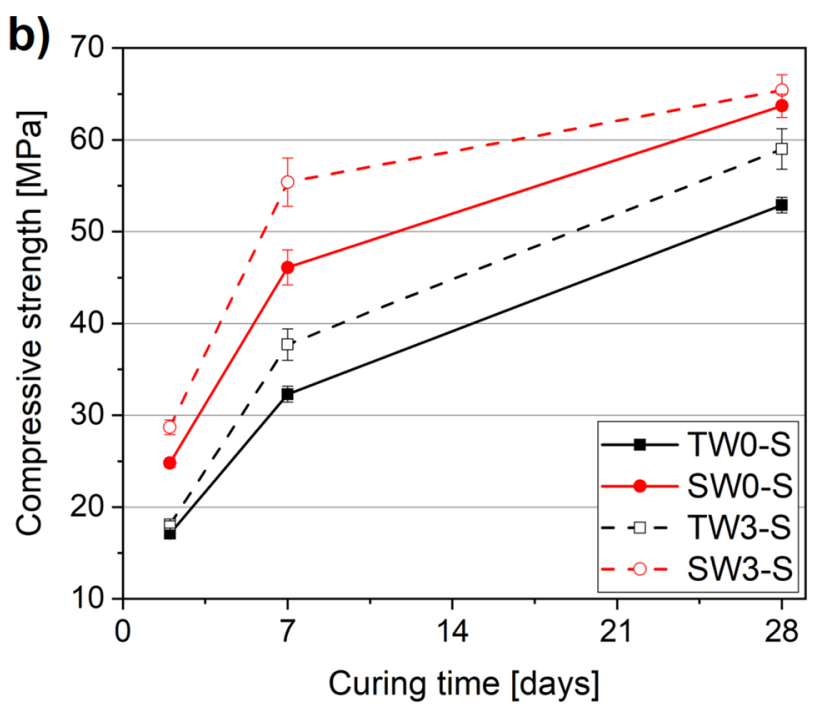

Fig. 7 Compressive strength development of cement mortars containing pozzolan-blended cement (a) and slag-blended cement (b)

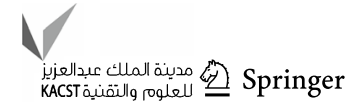



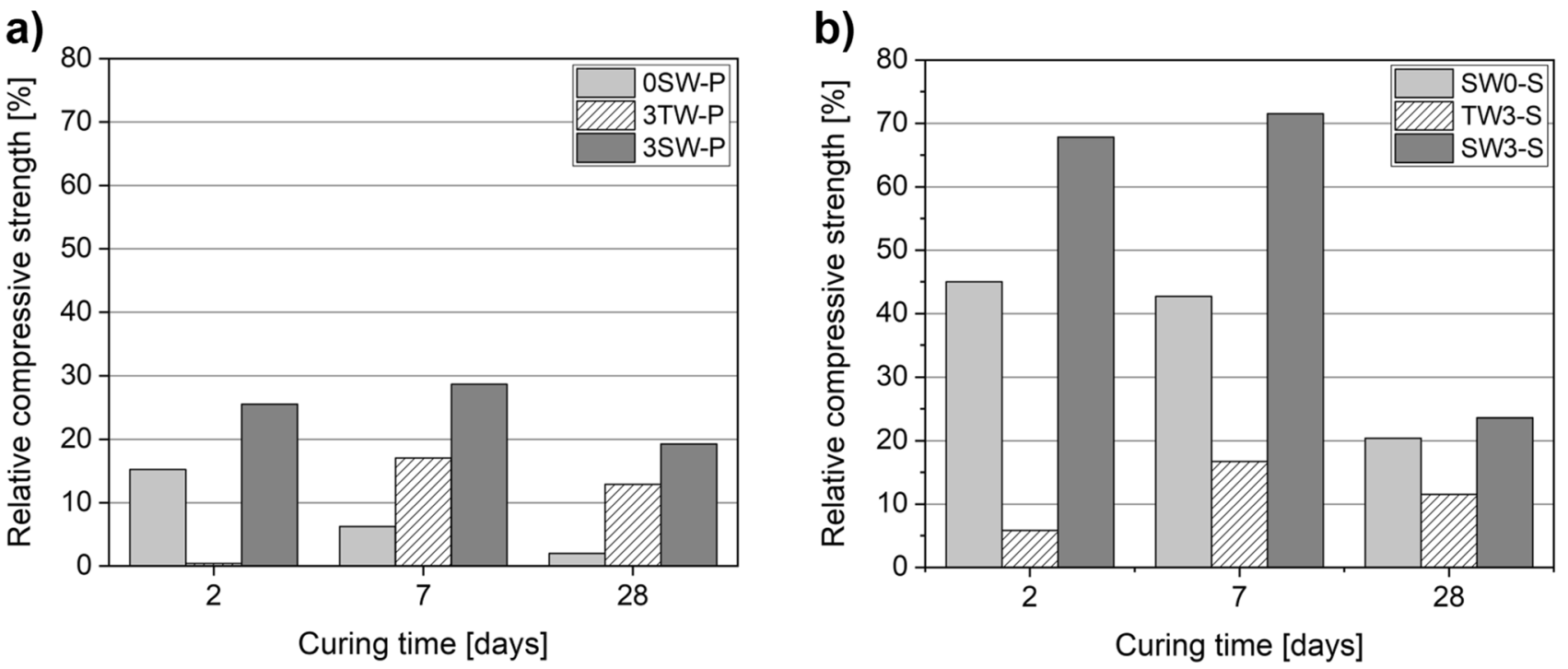

Fig. 8 Relative compressive strength of cement mortars in comparison to control freshwater-mixed mortar based on pozzolan-blended cement (a) and slag-blended cement (b)

development was definitely a result of the combination of NS with seawater, which resulted in the highest relative strength values in the early days of hydration.

The results obtained in this study are in line with previous findings, showing that cement type has a particularly significant effect on cementitious composites mixed with sea water, being highly beneficial when Al-rich SCMs are incorporated in the mixture. Li et al. (2018a) have reported that low water-to-binder, high strength cement paste mixtures containing slag exhibit higher early strength values than SF-incorporated mixtures, while Otsuki et al. (2012) have reported higher compressive strength for up to 90 days of hydration. Similarly, Etxeberria and Gonzalez-Corominas (2018) have reported $11 \%$ higher 28 -d compressive strength improvements in concrete containing slag-blended cement. Work undertaken by Cheng et al. (2018) on the effects of adding $5 \mathrm{wt} \%$ and $10 \%$ of MK, as well as a combination of $10 \%$ of MK with $10 \%$ of GGBFS, have shown that increases in SCM content lead to substantial improvements in early and 28-day strength, with a range of improvement similar to that found in this study.

\section{Flexural strength}

The flexural strength development of cement mortars is presented in Fig. 9. Similarly to the compressive strength results, a clear effect of the interaction between seawater and the type of cement used was reflected in flexural strength development. In the case of pozzolan-blended cement (Fig. 9a), seawater exhibited early flexural strength improvements, while at 28 days of curing the flexural strength of SW0-P was even $13 \%$ lower as compared to TW0-P. In addition, a noticeable effect of NS on the acceleration of early strength development was observed, but after 28 days of curing TW0-P and TW3-P exhibited comparable flexural strength values. In contrast, due to a slightly negative effect of seawater on flexural strength, the incorporation of NS in the seawater-mixed mortar, facilitated strength improvements, but specimen SW3-S exhibited worse performance than the TW3-P specimen. A different trend in flexural strength development was visible in specimens produced with slag-blended cement. Clearly, seawater facilitates the development of the flexural strength of mortars. Specimen SW0-S exhibited respectively $22 \%$ and $29 \%$ higher flexural strength after 2 and 7 days of curing, as compared to TW0-S. However, after 28 days of curing this value was higher by only $18 \%$. This clearly confirms that seawater has a significant effect on slag-blended cement within the first 7 days of hydration and is in line with earlier observations in the calorimetry and compressive strength sections above. Similarly to the case of pozzolan-blended cement, the incorporation of NS, supported flexural strength development. A mixture of freshwater and NS (TW3-S) resulted in 10\% higher 28 day flexural strength, as compared with TW0-P. Moreover, a combination of seawater with NS was most beneficial for the strength development of slag-blended cement mixtures and as a result specimen SW3-S almost reached its 28 days flexural strength value after just 7 days of curing. However, after 28 days of hydration SW0-S and SW3-S exhibited comparable strength values, followed by the TW3-S specimen.

The results reported here are in line with other available, however limited, studies related to the flexural and tensile strengths of seawater-mixed cementitious composites. Etxeberria et al. (2016b) have reported that concretes with varied 

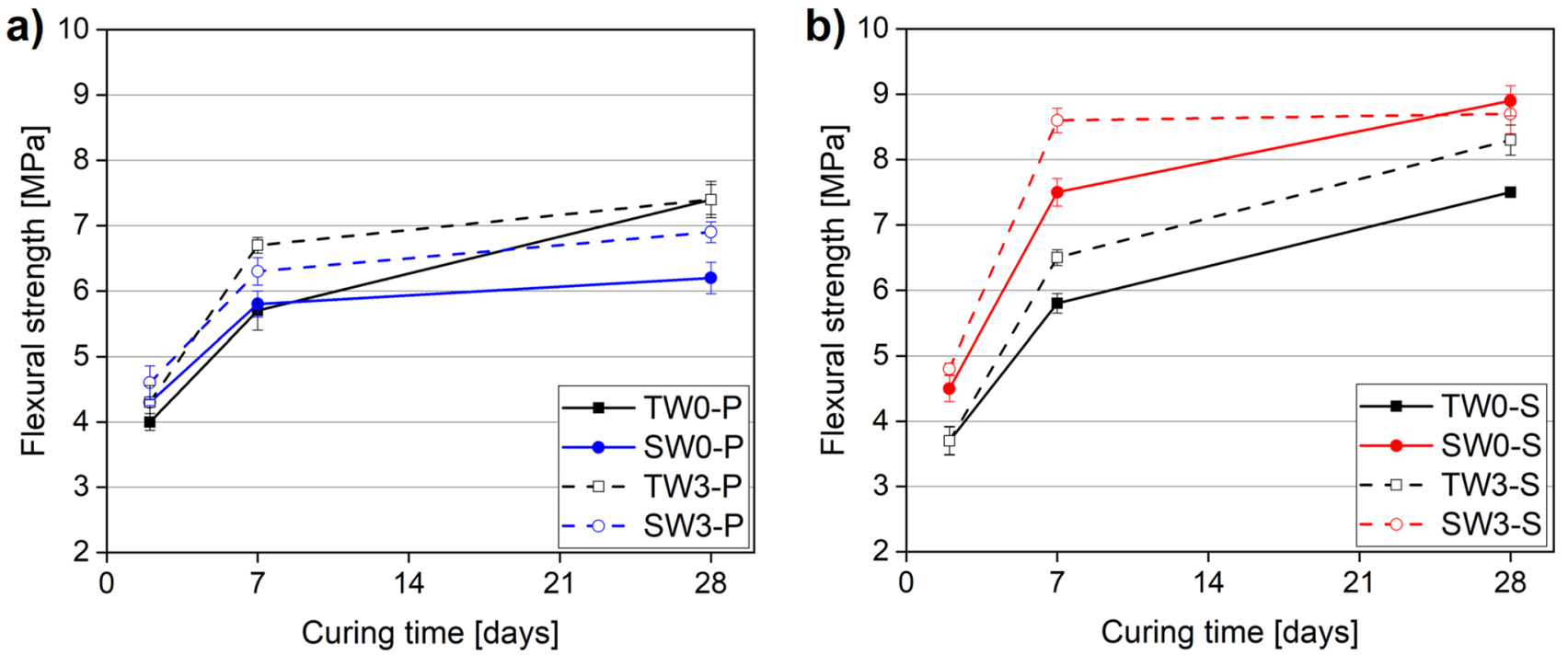

Fig. 9 Flexural strength development of cement mortars containing pozzolan-blended cement (a) and slag-blended cement (b)

contents of recycled aggregate concrete, produced with slagblended cement and seawater, on average exhibited between 11 and $18 \%$ higher 28 day flexural strength, than freshwater- and seawater-mixed concrete produced with OPC. In addition, a higher modulus of elasticity in slag-blended cement seawater-mixed concrete was reported. In the case of OPC concrete, Younis et al. (2018) have reported a slight increase in split-tensile strength in the early days, but, after 28-day and 56 days seawater lead to a slight decrement in split-tensile strength. A similar observation was reported by Etxeberria et al. (2016b); that seawater has a rather minor effect on the flexural strength of OPC concrete, after 28 days of curing. Our observations show that the reaction rate of slag-blended cement with seawater is much higher than in case of pozzolan-blended cement, which means that flexural strength improvements can still be observed after 28 days of curing. In the case of pozzolan-blended cement, this effect can only be observed in the early days of hydration. Additionally, the presence of NS has a significant effect on accelerating the early development of the flexural strength of mortars, but, after 28 days of curing the effect is rather limited, within a range of 10\% (Skoczylas and Rucińska 2018b; Abd Elrahman et al. 2019).

\section{Water accessible porosity and water sorptivity}

Water accessible porosity and water absorption coefficient values are depicted in Fig. 10. The water accessible porosity test results show that, in general, slag-blended cement mortars exhibited lower water accessible porosity values than the pozzolan-based cement mortars. In the case of pozzolanbased cement mortars, the highest water absorption value was obtained by TW0-P, with the other specimens exhibiting

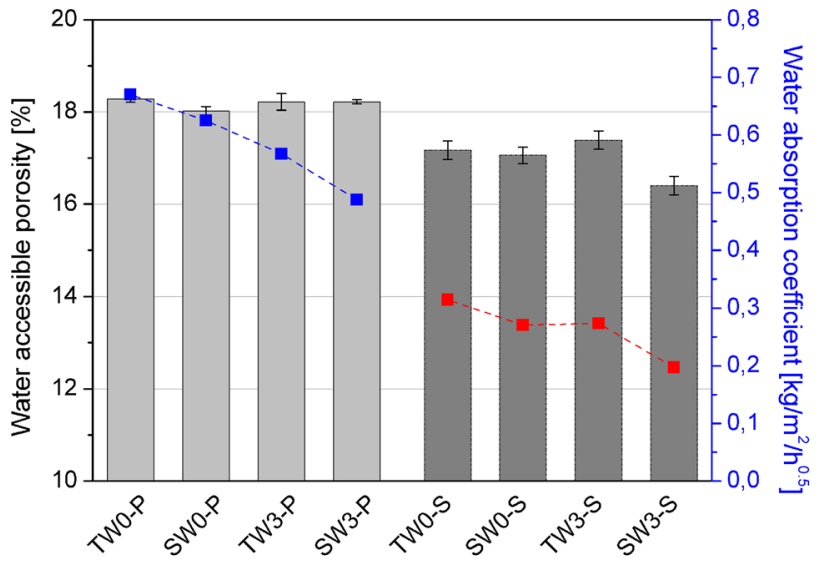

Fig. 10 Water accessible porosity and water absorption coefficient of cement mortars after 28 days of curing

slightly lower porosity values. Nevertheless, no significant changes between specimens were reported. Similarly, in the case of slag-blended cement, no significant differences between the TW0-S and SW0-S specimens was observed, while in case of TW3-S a slight increment in porosity was actually observed. Only specimen SW3-S exhibited a statistically significant reduction of water porosity. However, the effect of seawater and NS was more pronounced in in the case of decrements in specimens' water sorptivity. The use of seawater exhibited a noticeable effect on decreasing the water absorption coefficient of mortars containing both types of cements. In addition, the presence of NS in the mixture lead to a further decrement in this parameter, which is in line with the work of other researchers (Du and Pang 2015; Abd Elrahman et al. 2019; Tsampali et al. 2019). In both 
cases, the best performance was found for specimens SW3-P and SW3-S, showing that a combination of seawater and NS was the most beneficial in decreasing specimens' sorptivity. Many authors (Otsuki et al. 2015; Etxeberria et al. 2016a, b; Khatibmasjedi et al. 2019) have reported that seawater contributes to decreases in the water absorption and sorptivity of cement mortars and concretes, irrespective of the type of cement used. A possible explanation for this improvement is the formation of Friedel's salt, which precipitates in the pores thus refining the microstructure and improving the permeability of the composite ( $\mathrm{Li}$ et al. 2018a; Wang et al. 2018; Bertola et al. 2019).

\section{Thermogravimetric analysis}

Thermogravimetric analysis was performed to determine the amount of $\mathrm{CH}$ present and to estimate the amount of Friedel's salt, in the cement pastes produced with seawater. The $\mathrm{CH}$ content was calculated according to Eq. (2) and is depicted in Fig. 11. Typically, the initial amount of $\mathrm{CH}$ in cement paste depends on the type of cement used, with specimens made of pozzolan- and slag-blended cement exhibiting significantly lower amounts of $\mathrm{CH}$ content, as compared to plain OPC paste (Sisomphon and Franke 2011; Sikora et al. 2019b). It can be seen that in both types of cements, $\mathrm{CH}$ content increased gradually until 28 days of curing; this being attributable to the fact that both binders used in this study were low heat cements, in which the cement hydration process is moderate. At up to 28 days of curing, the $\mathrm{CH}$ content in specimens mixed with seawater was higher than when compared to freshwater mixed specimens. A similar observation was reported by Montanari et al. (2019), where fly ash-blended cement paste mixed with seawater exhibited a gradual increment in $\mathrm{CH}$ content, until up to 28 days of hydration, with the amount of $\mathrm{CH}$ at later ages decreasing, due to the pozzolanic reaction of fly ash. Surprisingly, in the case of slag-blended cement (Fig. 11b) after 2 and 7 days of curing, a slightly lower $\mathrm{CH}$ content was reported in seawater-mixed specimens, as compared to the corresponding freshwater-mixed specimens. This is most probably attributable to an extensive hydration process, which was apparent in the results of calorimetric studies and in the rapid strength development of composites, though this aspect requires further investigation. It can be clearly seen that specimens containing NS generally exhibited lower $\mathrm{CH}$ contents at all tested ages. This phenomena can be attributed to the remarkable pozzolanic activity of NS, which results in reaction of NS with the available $\mathrm{CH}$ and the production of more calcium silicate hydrate (C-S-H) gel (Zhang et al. 2019).

Although accurate quantification of Friedel's salt content from TG is complex, due to the overlapping ranges of thermal decomposition of the constituent parts of other pastes (Shi et al. 2017; Montanari et al. 2019), the TG method can be adapted for tracking specimens' general trends. Friedel's salt content (\% by weight of paste) was determined from TG curves, based on the mass loss between 230 and $380{ }^{\circ} \mathrm{C}$ (Montanari et al. 2019). Similarly to other research (Parthasarathy et al. 2017; Cheng et al. 2018; Wang et al. 2018; Bertola et al. 2019), in this study Friedel salt's was not detected in the early days of hydration ( 2 days). After 7 days of curing, Friedel's salt content in specimens $0 \mathrm{SW}-\mathrm{P}, 3 \mathrm{SW}-\mathrm{S}, 0 \mathrm{SW}-\mathrm{S}$ and $3 \mathrm{SW}-\mathrm{S}$ ranged from 1.4 to $1.83 \%$, while after 28 days of curing the amount increased and ranged from 2.2 to $2.5 \%$. This range is in line with Montanari et al. (2019) and confirms
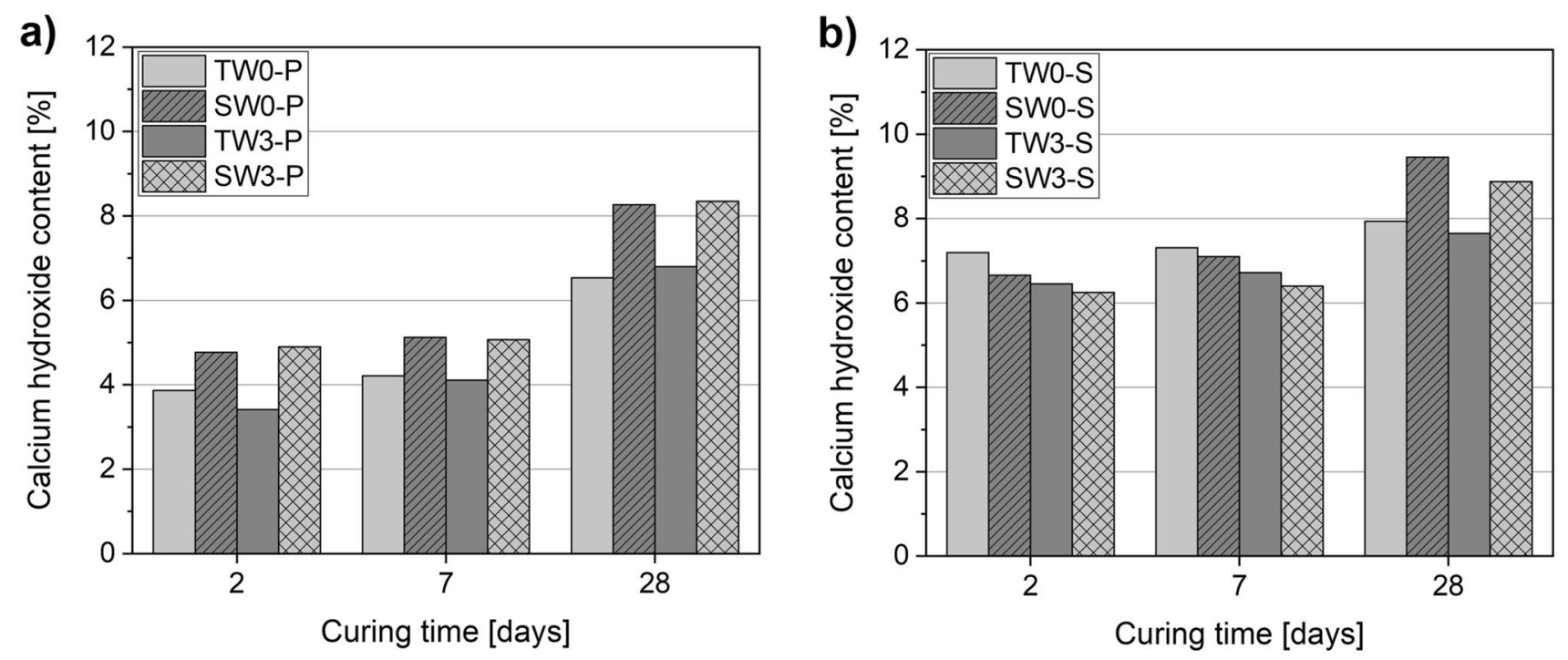

Fig. 11 Calcium hydroxide content after 2, 7 and 28 days of curing in pozzolan-blended (a) and slag-blended (b) cement

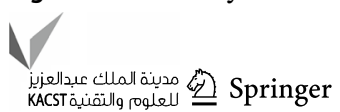


the occurrence of the chloride immobilization process in the hydrating cement matrix.

\section{Conclusions}

Based on the experimental results, the following conclusions can be drawn:

1. Seawater has an accelerating effect on the cement hydration process, but reaction kinetics are highly dependent on the type of cement used. In both types of cement, significant acceleration of early hydration was observed, but only slag-blended cement exhibited high cumulative heat release. This is attributable to additional reactions between seawater and alumina rich phases. The incorporation of NS leads to a significant enhancement of the hydration process, especially in the early days of hydration.

2. As a result of the acceleration of the cement hydration process, seawater contributes to decreasing the initial and final setting times of cement, with this effect being even more pronounced when a combination of seawater and NS is used.

3. The use of seawater as a mixing water results in an increment in the yield-stress of cement pastes, as well as in a decrement of the consistency of cement mortars. A combination of NS and seawater leads to an even stronger flocculation of the cementitious system, due to instability of NS in a seawater environment.

4. Seawater has a beneficial effect on the flexural and compressive strength development of cement pastes and mortars, especially in the early days of hydration. However, depending on the type of cement used, improvement in 14 days and 28 days strengths can also be achieved. This can be attributed to the additional reaction of seawater with the SCMs available in the cement. The study showed that alumina rich SCM (slag) is more efficient than pozzolan SCM (suevite). A combination of seawater and NS resulted in a noticeable improvement in the flexural and compressive strength of pastes and mortars, at up to 28 days of hydration. However, the most substantial contribution was reported at 7 days of curing. This effect is attributable to the nucleating, filling and pozzolanic activity of NS, which results in an acceleration of the cement hydration process and in the production of additional $\mathrm{C}-\mathrm{S}-\mathrm{H}$ gel.

5. Depending on the type of cement used, the incorporation of seawater contributes in different degrees to an improvement of the transport properties of cement mortars (a decrement of water accessible porosity and sorptivity). In addition, NS refines the microstructure of a cement matrix and thus a combination of seawater and
NS is beneficial for improving the transport properties of mortars.

Acknowledgements Open Access funding provided by Projekt DEAL. This project has received funding from the European Union's Horizon 2020 research and innovation program under the Marie SkłodowskaCurie Grant agreement no. 841592. P.S. is supported by the Foundation for Polish Science (FNP).

\section{Compliance with ethical standards}

Conflict of interest On behalf of all authors, the corresponding author states that there is no conflict of interest.

Open Access This article is licensed under a Creative Commons Attribution 4.0 International License, which permits use, sharing, adaptation, distribution and reproduction in any medium or format, as long as you give appropriate credit to the original author(s) and the source, provide a link to the Creative Commons licence, and indicate if changes were made. The images or other third party material in this article are included in the article's Creative Commons licence, unless indicated otherwise in a credit line to the material. If material is not included in the article's Creative Commons licence and your intended use is not permitted by statutory regulation or exceeds the permitted use, you will need to obtain permission directly from the copyright holder. To view a copy of this licence, visit http://creativecommons.org/licenses/by/4.0/.

\section{References}

Abd El-Aleem S, Ragab AER (2014) Physico-mechanical properties and microstructure of blended cement incorporating nano-silica. Int J Eng Res Technol 3(7):339-358

Abd El-Aleem S, Ragab AER (2015) Chemical and physico-mechanical properties of composite cements containing micro- and nanosilica. Int J Civ Eng Technol 6(5):45-64

Abd Elrahman M, Chung SY, Sikora P, Rucinska T, Stephan D (2019) Influence of nanosilica on mechanical properties, sorptivity, and microstructure of lightweight concrete. Materials 12(19):3078. https://doi.org/10.3390/ma12193078

Abdel Gawwad HA, Abd El-Aleem S, Faried AS (2017) Influence of nano-silica and -metakaolin on the hydration characteristics and microstructure of air-cooled slag blended cement mortar. Geosyst Eng 20(5):276-285. https://doi.org/10.1080/12269 328.2017.1323678

Abdel-Magid TI et al (2016) Influence of seawater in strengths of concrete mix design when used in mixing and curing. Key Eng Mater 711:382-389. https://doi.org/10.4028/www.scientific.net/ KEM.711.382

Augustyniak A, Cendrowski K, Nawrotek P, Barylak M, Mijowska E (2016) Investigating the interaction between Streptomyces sp. and titania/silica nanospheres. Water Air Soil Pollut 227:230. https:// doi.org/10.1007/s11270-016-2922-z

Babick F (2016) Suspensions of colloidal particles and aggregates. Springer International Publishing, Cham

Basheer M, Barbhuiya S (2009) Different types of cement used in concrete. ICE manual of construction materials. Chapter 6, vol 1. Edtd. Thomas Telford, pp 87-89. ISBN 978-0-7277-3642-0

Bautista JW, Crockett JB, Liu BA, Obra TJ, Roxas CL (2015) Drying shrinkage of fly ash mortar mixed with seawater. Appl Mech Mater 802:118-123 https://www.scientific.net/AMM.802.118

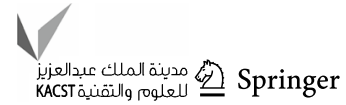


Bentz DP, Ferraris CF, Jones SZ, Lootens D, Zunino F (2017) Limestone and silica powder replacements for cement: early-age performance. Cem Concr Compos 78:43-56. https://doi.org/10.1016/j. cemconcomp.2017.01.001

Bertola F, Gastaldi D, Canonico F (2019) Behavior of specialty binders mixed with seawater. Adv Civ Eng Mater 8(2):96-109. https://doi. org/10.1520/ACEM20180107

Bretsnajdrova E, Svoboda L, Zelenka J (2010) Determination of particle shape and size distribution of model types of nanomaterials. J Electr Eng 61(5):302-304

Chen Y, Den YF, Li MQ (2016) Influence of nano-SiO2 on the consistency, setting time, early-age strength, and shrinkage of composite cement pastes. Adv Mater Sci Eng 2016:5283706. https://doi. org/10.1155/2016/5283706

Cheng S, Shui Z, Sun T, Huang Y, Liu K (2018) Effects of seawater and supplementary cementitious materials on the durability and microstructure of lightweight aggregate concrete. Constr Build Mater 190:1081-1090. https://doi.org/10.1016/j.conbuildma t.2018.09.178

Daghlan Sofla SJ, James LA, Zhang Y (2018) Insight into the stability of hydrophilic silica nanoparticles in seawater for enhanced oil recovery implications. Fuel 216(2018):559-571. https://doi. org/10.1016/j.fuel.2017.11.091

Demir Y, Yaprak H, Simsek O (2010) The effect of sea water on the properties of concrete with silica fume admixture. Cem Wapno Beton 1:22-30

Dhondy T, Remennikov A, Shiekh MN (2019) Benefits of using sea sand and seawater in concrete: a comprehensive review. Aust J Struct Eng. https://doi.org/10.1080/13287982.2019.1659213

Du H, Pang SD (2015) Effect of colloidal nano-silica on the mechanical and durability performances of mortar. Key Eng Mater 629-630:443-448. https://doi.org/10.4028/www.scientific.net/ KEM.629-630.443

El-Feky MS, Youssef P, El-Tair AM, Ibrahim S, Serag M (2019) Effect of nano silica addition on enhancing the performance of cement composites reinforced with nano cellulose fibers. AIMS Mater Sci 6(6):864-883. https://doi.org/10.3934/matersci.2019.6.864

Etxeberria M, Gonzalez-Corominas A (2018) Properties of plain concrete produced employing recycled aggregates and sea water. Int J Civ Eng 16(9):993-1003. https://doi.org/10.1007/s4099 9-017-0229-0

Etxeberria M, Fernandez JM, Limeira J (2016a) Secondary aggregates and seawater employment for sustainable concrete dyke blocks production: case study. Constr Build Mater 113:586-595. https:// doi.org/10.1016/j.conbuildmat.2016.03.097

Etxeberria M, Gonzalez-Corominas A, Pardo P (2016b) Influence of seawater and blast furnace cement employment on recycled aggregate concretes' properties. Constr Build Mater 115:496-505. https ://doi.org/10.1016/j.conbuildmat.2016.04.064

Fernanda RL, Goncalves JP, Dweck J, da Cunha ALC (2017) Evaluation of influence of salt in the cement hydration to oil wells. Mater Res 20(2):7430747. https://doi. org/10.1590/1980-5373-MR-2017-0049

Flores YC, Cordeiro GC, Filho RDT, Tavares LM (2017) Performance of Portland cement pastes containing nano-silica and different types of silica. Constr Build Mater 146:524-530. https://doi. org/10.1016/j.conbuildmat.2017.04.069

Govindarajan D, Gopalakrishnan R (2011) Spectroscopic studies on indian Portland cement hydrated with distilled water and sea water. Front Sci 1(1):21-27. https://doi.org/10.5923/j.fs.20110 101.04

Guo Q, Chen L, Zhao H, Admilson J, Zhang W (2018) The effect of mixing and curing sea water on concrete strength at different ages. MATEC Web Conf 142:02004. https://doi.org/10.1051/ matecconf/201814202004
Heikal M, Abd-El Aleem S, Morsi WM (2016) Durability of composite cements containing granulated blast-furnace slag and silica nanoparticles. Indian J Eng Mater Sci 23(1):88-100

Hou P, Qian J, Cheng X, Shah SP (2015) Effects of the pozzolanic reactivity of nanoSiO ${ }_{2}$ on cement-based materials. Cem Concr Compos 55:250-258. https://doi.org/10.1016/j.cemconcomp .2014 .09 .014

Ishikawa Y, Fukutome K, Otsuki N, Nishida T (2014) Strength development of fly ash concrete using sea water as mixing water. Cem Sci Concr Technol 68:315-322. https://doi.org/10.14250/cemen t.68.315

Jiangtao Y, Keke L, Qingfeng X, Zhanhong L, Lijun O (2019) Feasibility of using seawater to produce ultra-high ductile cementitious composite for construction without steel reinforcement. Struct Concr 20:774-785. https://doi.org/10.1002/suco.201800116

Jun Y, Yoon S, Oh JE (2017) A comparison study for chloridebinding capacity between alkali-activated fly ash and slag in the use of seawater. Appl Sci 7:971. https://doi.org/10.3390/ app7100971

Kaushik SK, Islam S (1995) Suitability of seawater for mixing structural concrete exposed to a marine environment. Cem Concr Compos 17(3):177-185

Khatibmasjedi M, Ramanthan S, Suraneni P, Nanni A (2019) Shrinkage behavior of cementitious mortars mixed with seawater. Adv Civ Eng Mater 8(2):64-78. https://doi.org/10.1520/ACEM20180110

Kotsay G (2017) Peculiarities of hydration of Portland cement with synthetic nano-silica. Sel Sci Pap J Civ Eng 12:101-106. https:// doi.org/10.1515/sspjce-2017-0025

Krivenko PV, Sanytsky M, Kropyvnytska T (2019) The effect of nanosilica on the early strength of alkali-activated Portland composite cements. Solid Stat Phenom 296:21-26. https://doi.org/10.4028/ www.scientific.net/SSP.296.21

Kucche KJ, Jamkar SS, Sadgir A (2015) Quality of water for making concrete: a review of literature. Int J Sci Res Publ 5:1-10

Land G, Stephan D (2012) The influence of nano-silica on the hydration of ordinary Portland cement. J Mater Sci 47(2):1011-1017. https://doi.org/10.1007/s10853-011-5881-1

Li Q, Geng H, Shui Z, Huang Y (2015) Effect of metakaolin addition and seawater mixing on the properties and hydration of concrete. Appl Clay Sci 115:51-60. https://doi.org/10.1016/j. clay.2015.06.043

Li YL, Zhao XL, Singh RK, Al-Saadi S (2016) Experimental study on seawater and sea sand concrete filled GFRP and stainless steel tubular stub columns. Thin Walled Struct 106:390-406. https:// doi.org/10.1016/j.tws.2016.05.014

Li H, Farzadnia N, Shi C (2018a) The role of seawater in interaction of slag and silica fume with cement in low water-to-binder ratio pastes at the early age of hydration. Constr Build Mater 185:508518. https://doi.org/10.1016/j.conbuildmat.2018.07.091

Li YL, Teng JG, Zhao XL, Singh Raman RK (2018b) Theoretical model for seawater and sea sand concrete-filled circular FRP tubular stub columns under axial compression. Eng Struct 160:71-84. https://doi.org/10.1016/j.engstruct.2018.01.017

Li LG, Chen XQ, Chu SH, Ouyang Y, Kwan AKH (2019) Seawater cement paste: effects of seawater and roles of water film thickness and superplasticizer dosage. Constr Build Mater 229:116862. https://doi.org/10.1016/j.conbuildmat.2019.116862

Liard M, Oblak L, Hachim M, Vachon M, Lootens D (2014) Impact of viscosity on hydration kinetics and setting properties of cementitious materials. Adv Civ Eng Mater 3(2):117-126. https://doi. org/10.1520/ACEM20130096

Lim ED, Roxas CL, Gallardo R, Nishida T, Otsuki N (2015) Strength and corrosion behavior of mortar mixed and/or cured with seawater with various fly ash replacement ratios. Asian J Civ Eng 16(6):835-849 
Liu J, Li Q, Xu S (2015) Influence of nanoparticles on fluidity and mechanical properties of cement mortar. Constr Build Mater 101:892-901. https://doi.org/10.1016/j.conbuildmat.2015.10.149

Mbadike EM, Elinwa AU (2011) Effect of salt water in the production of concrete. Niger J Technol 30(2):105-110

Meacci V, Ricci S, Bruehwiler A, Lootens D (2016) Compact ultrasound board for measurement of concrete compressive strength. In: 2016 IEEE international ultrasonics symposium (IUS), pp 1-4. https://doi.org/10.1109/ULTSYM.2016.7728586

Metin CO, Lake LW, Miranda CR, Nguyen QP (2011) Stability of aqueous silica nanoparticle dispersions. J Nanopart Res 13:839850. https://doi.org/10.1007/s11051-010-0085-1

Mijowska E, Cendrowski K, Barylak M, Konicki W (2015) Sandwich-like mesoporous silica flakes for anticancer drugtransport-synthesis, characterization and kinetics release study. Coll Surf B Biointerfaces 136:119-125. https://doi. org/10.1016/j.colsurfb.2015.09.007

Mohammed TK, Hamada H, Yamaji T (2004) Performance of seawater-mixed concrete in the tidal environment. Cem Concr Res 34:593-601. https://doi.org/10.1016/j.cemconres.2003.09.020

Montanari L, Suraneni P, Tsui-Chang M, Khatibmasjedi M, Ebead U, Weiss J, Nanni A (2019) Hydration, pore solution, and porosity of cementitious pastes made with seawater. J Mater Civ Eng 31(8):04019154. https://doi.org/10.1061/(ASCE)MT.19435533.0002818

Ojeda-Farías O, Hebraud P, Lootens D, Liard M, Mendoza-Rangel JM (2019) Thixotropy of reactive suspensions: the case of cementitious materials. Constr Build Mater 212:121-129. https ://doi.org/10.1016/j.conbuildmat.2019.03.319

Olivas A, Ferraris CF, Martys N, Garboczi EJ, Toman B, George WL (2017) Certification of SRM 2493: standard reference mortar for rheological measurements. NIST Spec Publ. https://doi. org/10.6028/NIST.SP.260-187

Otsuki N, Saito T, Tadokoro Y (2012) Possibility of seawater as mixing water in concrete. J Civ Eng Archit 10:1273-1279. https:// doi.org/10.17265/1934-7359/2012.10.002

Otsuki N, Hamada H, Takeda N, Imamoto K, Yamaji T, Habuchi T, Nishida T (2015) Technical Committee on the use of sea water in concrete (Committee Report: JCI-TC121A) Technical Committee Reports 2014-Japan Concrete Institute

Parthasarathy P, Hanif A, Shao H, Li Z (2017) Microstructural and morphological studies of ordinary Portland cement paste and fly ash based geopolymer in the presence of chloride ions. In: 71st RILEM Annual Week \& ICACMS 2017, Chennai, India, 3rd-8th September 2017

Potapov VV, Efimenko YV, Gorev DS (2019) Modification of concrete by hydrothermal nanosilica. Nanotechnol Constr 11:248265. https://doi.org/10.15828/2075-8545-2019-11-3-248-265

Quercia G, Lazaro A, Geus JW, Brouwers HJH (2013) Characterization of morphology and texture of several amorphous nanosilica particles used in concrete. Cem Concr Compos 44:77-92. https://doi.org/10.1016/j.cemconcomp.2013.05.006

Sanytsky M, Marushchak U, Olevych Y, Novytskyi Y (2020) Nanomodified ultra-rapid hardening Portland cement compositions for high strength concretes. In: Blikharskyy Z, Koszelnik P, Mesaros P (eds) Proceedings of CEE 2019. CEE 2019. Lecture Notes in Civil Engineering, vol 47. Springer, Cham, pp 392-399. https://doi.org/10.1007/978-3-030-27011-7_50

Scrivener K, Snellings R, Lothenbach B (2016) A practical guide to microstructural analysis of cementitious materials. Taylor \& Francis, Boca Raton

Senff L, Labrincha JA, Ferreira VM, Hotza D, Repette WL (2009) Effect of nano-silica on rheology and fresh properties of cement pastes and mortars. Constr Build Mater 23(7):2487-2491. https ://doi.org/10.1016/j.conbuildmat.2009.02.005
Shaikh FUA, Dobson J (2019) Effect of fly ash on compressive strength and chloride binding of seawater-mixed mortars. J Sustain Cem Based Mater. https://doi.org/10.1080/21650 373.2019.1582370

Shi Z, Shui Z, Li Q, Geng H (2015) Combined effect of metakaolin and sea water on performance and microstructures of concrete. Constr Build Mater 74:57-64. https://doi.org/10.1016/j.conbu ildmat.2014.10.023

Shi Z, Geiker MR, Lothenbach B, De Weerdt K, Garzon SF, EnemarkRasmussen K, Skibsted J (2017) Friedel's salt profiles from thermogravimetric analysis and thermodynamic modelling of Portland cement-based mortars exposed to sodium chloride solution. Cem Concr Compos 78:73-83. https://doi.org/10.1016/j.cemconcomp .2017 .01 .002

Sikora P, Abd Elrahman M, Stephan D (2018) The influence of nanomaterials on the thermal resistance of cement-based compositesa review. Nanomater 8(7):465. https://doi.org/10.3390/nano8 070465

Sikora P, Abd Elrahman M, Chung SY, Cendrowski K, Mijowska E, Stephan D (2019a) Mechanical and microstructural properties of cement pastes containing carbon nanotubes and carbon nanotube-silica core-shell structures, exposed to elevated temperature. Cem Concr Compos 95:193-204. https://doi.org/10.1016/j.cemco ncomp.2018.11.006

Sikora P, Cendrowski K, Abd Elrahman M, Chung SY, Mijowska E, Stephan D (2019b) The effects of seawater on the hydration, microstructure and strength development of Portland cement pastes incorporated with colloidal silica. Appl Nanosci. https:// doi.org/10.1007/s13204-019-00993-8

Singh LP, Bhattacharyya SK, Mishra G, Ahalawat S (2011) Functional role of cationic surfactant to control the nano size of silica powder. Appl Nanosci 1:117-122. https://doi.org/10.1007/s1320 4-011-0016-1

Sisomphon K, Franke L (2011) Evaluation of calcium hydroxide contents in pozzolanic cement pastes by a chemical extraction method. Constr Build Mater 25:191-194. https://doi.org/10.1016/j.conbu ildmat.2010.06.039

Skoczylas K, Rucińska T (2018a) Strength and durability of cement mortars containing nanosilica and waste glass fine aggregate. Cem Wapno Beton 23(3):206-215

Skoczylas K, Rucińska T (2018b) The effects of waste glass cullets and nanosilica on the long-term properties of cement mortars. E3S Web Conf 49:102. https://doi.org/10.1051/e3sconf/20184900102

Szymanowski J, Sadowski Ł (2019) Functional and adhesiveproperties of cement-based overlays modified with amorphous silica nanospheres. J Adhes. https://doi.org/10.1080/00218464.2019.166341

Tawfik TA, El-Yamani MA, Abd El-Aleem S, Gabr AS, Abd El-Hafez GM (2018) Effect of nano-silica and nano-waste material on durability and corrosion rate of steel reinforcement embedded in highperformance concrete. Asian J Civ Eng. https://doi.org/10.1007/ s42107-018-0093-5

Teng JG, Xiang Y, Yu T, Fang Z (2019) Development and mechanical behaviour of ultra-high-performance seawater sea-sand concrete. Adv Struct Eng. https://doi.org/10.1177/1369433219858291

Tsampali E, Tsardaka EC, Pavlidou E, Paraskevopoulos KM, Stefanidou M (2019) Comparative study of the properties of cement pastes modified with nano-silica and nano-alumina. Solid State Phenom 286:133-144. https://doi.org/10.4028/www.scientific.net/ SSP.286.133

Tuoriniemi J et al (2014) Intermethod comparison of the particle size distributions of colloidal silica nanoparticles. Sci Tech Adv Mater 15:035009. https://doi.org/10.1088/1468-6996/15/3/035009

United Nations (2019) About the sustainable development goals. [Online]. https://www.un.org/sustainabledevelopment/sustainabl e-development-goals/. Accessed 17 Oct 2019

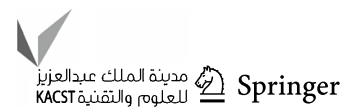


Wang J, Liu E, Li L (2018) Multiscale investigations on hydration mechanisms in seawater OPC paste. Constr Build Mater 191:891903. https://doi.org/10.1016/j.conbuildmat.2018.10.010

Wegian FM (2010) Effect of seawater for mixing and curing on structural concrete. IES J Part A Civ Struct Eng 3(4):235-243. https:// doi.org/10.1080/19373260.2010.521048

Xiao J, Qiang C, Nanni A, Zhang K (2017) Use of sea-sand and seawater in concrete construction: current status and future opportunities. Constr Build Mater 155:1101-1111. https://doi. org/10.1016/j.conbuildmat.2017.08.130

Xu Z, Zhou Z, Du P, Chen X (2016) Effects of nano-silica on hydration properties of tricalcium silicate. Constr Build Mater 125:11691177. https://doi.org/10.1016/j.conbuildmat.2016.09.003

Ye Q, Zhang Z, Kong D, Chen R (2007) Influence of nano-SiO addition on properties of hardened cement paste as compared with silica fume. Constr Build Mater 21:539-545. https://doi. org/10.1016/j.conbuildmat.2005.09.001
Yıldırım G, Dündar B, Alam B, Yaman IO, Sahmaran M (2018) Role of nanosilica on the early-age performance of natural pozzolanbased blended cement. Aci Mater J 115(6):969-980. https://doi. org/10.14359/51706848

Younis A, Ebead U, Suraneni P, Nanni A (2018) Fresh and hardened properties of seawater-mixed concrete. Constr Build Mater 190:276-286. https://doi.org/10.1016/j.conbuildmat.2018.09.126

Zhang X, Yang H, Yang Q, Du X, Li C, Cheng X (2019) Effects of particle size of colloidal nanosilica on hydration of Portland cement at early age. Adv Mech Eng 11:168781401982894. https://doi. org/10.1177/1687814019828948

Publisher's Note Springer Nature remains neutral with regard to jurisdictional claims in published maps and institutional affiliations. 